\title{
PTP1B and SHP2 in POMC neurons reciprocally regulate energy balance in mice
}

\author{
Ryoichi Banno,1 Derek Zimmer, ${ }^{1}$ Bart C. De Jonghe,1 Marybless Atienza, ${ }^{1}$ Kimberly Rak, ${ }^{1}$ \\ Wentian Yang, ${ }^{2}$ and Kendra K. Bence ${ }^{1}$
}

\begin{abstract}
1Department of Animal Biology, School of Veterinary Medicine, University of Pennsylvania, Philadelphia. ${ }^{2}$ Department of Orthopaedics, $\mathrm{RIH} /$ Brown University Alpert Medical School, Providence, Rhode Island.
\end{abstract}

\begin{abstract}
Protein tyrosine phosphatase 1B (PTP1B) and SH2 domain-containing protein tyrosine phosphatase-2 (SHP2) have been shown in mice to regulate metabolism via the central nervous system, but the specific neurons mediating these effects are unknown. Here, we have shown that proopiomelanocortin (POMC) neuronspecific deficiency in PTP1B or SHP2 in mice results in reciprocal effects on weight gain, adiposity, and energy balance induced by high-fat diet. Mice with POMC neuron-specific deletion of the gene encoding PTP1B (referred to herein as POMC-Ptp1 $b^{-/-}$mice) had reduced adiposity, improved leptin sensitivity, and increased energy expenditure compared with wild-type mice, whereas mice with POMC neuron-specific deletion of the gene encoding SHP2 (referred to herein as POMC-Shp2 $2^{-/-}$mice) had elevated adiposity, decreased leptin sensitivity, and reduced energy expenditure. POMC-Ptp1 $b^{-/-}$mice showed substantially improved glucose homeostasis on a high-fat diet, and hyperinsulinemic-euglycemic clamp studies revealed that insulin sensitivity in these mice was improved on a standard chow diet in the absence of any weight difference. In contrast, POMC$S h \mathbf{P}^{-/-}$mice displayed impaired glucose tolerance only secondary to their increased weight gain. Interestingly, hypothalamic Pomc mRNA and $\alpha$-melanocyte-stimulating hormone $(\alpha \mathrm{MSH})$ peptide levels were markedly reduced in POMC-Shp2 $2^{-/-}$mice. These studies implicate PTP1B and SHP2 as important components of POMC neuron regulation of energy balance and point to what we believe to be a novel role for SHP2 in the normal function of the melanocortin system.
\end{abstract}

\section{Introduction}

Obesity has become a major health concern worldwide (1). Currently there are few effective therapies for targeting obesity and its associated comorbidities in humans. The CNS has long been implicated in the control of energy balance, with the hypothalamus playing a key role as an integrator of metabolic information (reviewed in ref. 2). Thus, an important area of obesity research centers on understanding the neural signaling pathways that control energy balance.

Within the hypothalamus, first-order neurons in the arcuate nucleus (ARC) respond to circulating adiposity signals, such as insulin and leptin, and project to second-order neurons in the paraventricular nucleus (PVN), the dorsomedial hypothalamus $(\mathrm{DMH})$, and the lateral hypothalamus (LHA) to mediate effects on food intake and energy expenditure (3-7). Two distinct populations of first-order neurons synthesize either agouti-related protein $(\mathrm{AgRP})$ or proopiomelanocortin (POMC) and mediate opposing effects on energy balance $(4,8)$. The POMC precursor is cleaved into biologically active peptides, including $\alpha$-melanocyte-stimulating hormone ( $\alpha \mathrm{MSH})$, which binds to melanocortin-3 and -4 receptors on target second-order neurons (9). The adipocyte-secreted hormone leptin acts in the brain as a catabolic hormone to decrease appetite and increase energy expenditure via simultaneous suppression of AgRP neurons and stimulation of POMC neurons $(4,10,11)$.

The discovery of leptin initially offered the hope that obesity might be "cured" by exogenous leptin treatment (12). The efficacy of leptin therapy in obese humans, however, has been in large part disappointing due to the development of leptin resistance $(13,14)$.

Conflict of interest: The authors have declared that no conflict of interest exists. Citation for this article: J Clin Invest. 2010;120(3):720-734. doi:10.1172/JCI39620.
One mechanism leading to leptin resistance is inhibition of the intracellular leptin signaling cascade (15). An important regulator of leptin signaling is the protein tyrosine phosphatase PTP1B, which negatively regulates leptin signaling via direct dephosphorylation of Jak2 (16-18). Studies of mice with tissue-specific disruption of the Ptpn1 gene (encoding PTP1B) demonstrated that neuronal PTP1B deficiency results in reduced body weight and adiposity (due to increased energy expenditure). Deficiency of PTP1B in muscle, liver, or the brain improves insulin sensitivity (19-21). The specific population(s) of neurons mediating the effects of PTP1B on body weight and glucose homeostasis are unknown. Although PTP1B is expressed throughout the brain, it is highly enriched in the ARC of the hypothalamus, an important site of leptin action (16). From a therapeutic standpoint, inhibition of central PTP1B activity may be a promising approach to overcome leptin resistance in humans (22).

SHP2 is a broadly expressed non-receptor tyrosine phosphatase that has been implicated in the regulation of multiple signaling cascades, including leptin signaling (reviewed in refs. 23, 24). In vitro studies have shown that SHP2 promotes signaling from $\mathrm{Y}^{985}$ of the leptin receptor, resulting in enhanced activation of the ERK pathway $(25,26)$. These results are supported by studies of mice with selective deletion of SHP2 in postmitotic forebrain neurons (CaSKO mice), which have impaired leptin-induced ERK activation (27), presumably contributing to their obesity and leptin resistance. Another line of neuronal $S h p 2^{-/-}$mice also displays obesity and severe insulin resistance (28), highlighting SHP2 as a novel drug target for the treatment of metabolic syndrome (24). Since these studies were done in mice with broad neuronal deletion of SHP2, the specific neuronal population(s) mediating the metabolic effects of SHP2 deficiency is also unknown. 
A

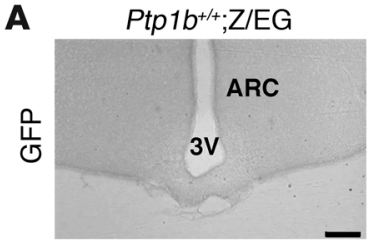

B

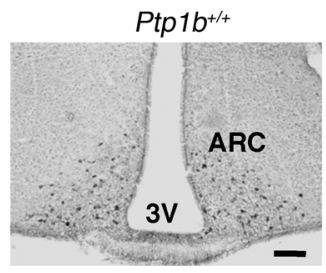

C

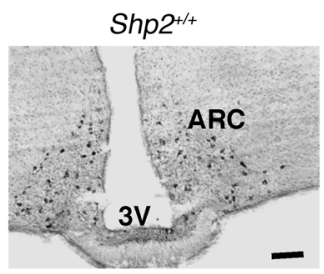

D
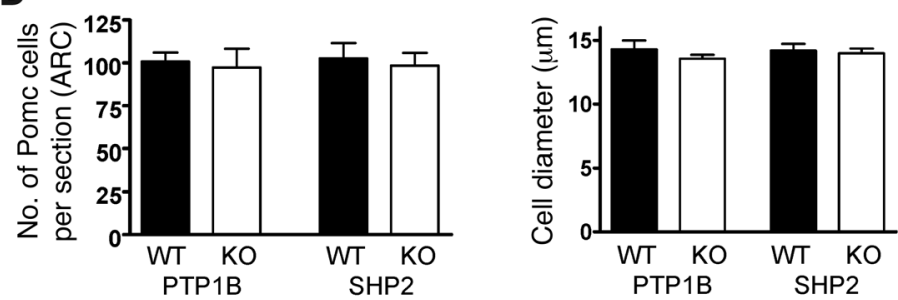

E
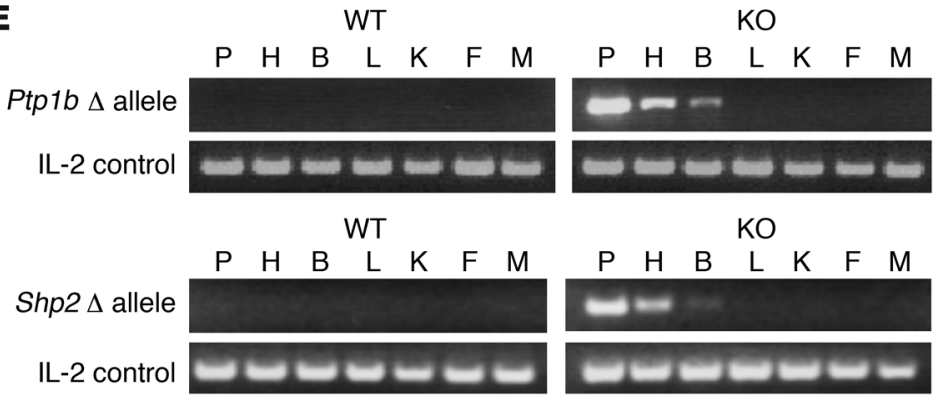

POMC-Ptp1 $1 b^{-/}$zoom

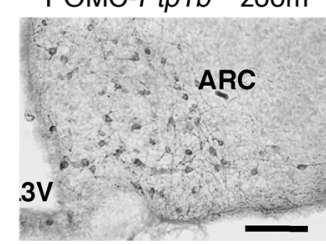

POMC-Shp2-- zoom

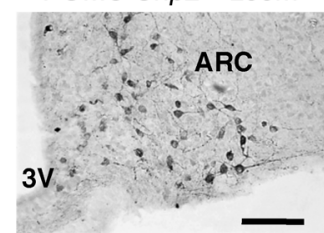

$\mathbf{F}$

$$
\frac{\text { Liver }}{\text { WT KO }} \frac{\text { Muscle }}{\text { WT KO }} \frac{\text { Adipose }}{\text { WT KO }} \frac{\text { Hypo }}{\text { WT KO }}
$$

PTP1B

SHP2 reprobe

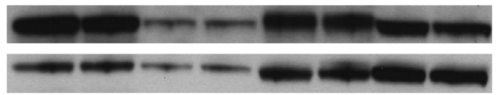

SHP2

$$
\frac{\text { Liver }}{\text { WT KO }} \frac{\text { Muscle }}{\text { WT KO }} \frac{\text { Adipose }}{\text { WT KO }} \frac{\text { Hypo }}{\text { WT KO }}
$$

ERK2 reprobe

POMC-expressing neurons play an important role in CNS control of energy balance through regulation of energy expenditure, food intake, and glucose homeostasis $(10,29)$. Mutations in the $P O M C$ gene in humans and rodents result in marked obesity, implicating this neuropeptide system as an essential component in the control of energy balance $(9,30)$. Deletion of the long form

\section{Figure 1}

Generation of mice with POMC neuron deficiency of PTP1B or SHP2. (A) Deletion efficiency of POMC-Cre as assessed by immunohistochemistry for GFP. Ptp $1 b^{+/+} ; \mathrm{Z} / \mathrm{EG}$ control hypothalamus (left) compared with POMC-Ptp $1 b^{-/-; / Z / E G ~ h y p o-~}$ thalamus (right). ( $B$ and $\mathbf{C}$ ) Immunohistochemistry for $\alpha \mathrm{MSH}$ was performed in colchicine-injected Ptp $1 b^{+/+}$or Shp2 $2^{+/+}$controls compared with POMC-Ptp $1 b^{-/-}$or -Shp2 $2^{-/-}$mice. 3V, third ventricle. Scale bars: $50 \mu \mathrm{m}$. (D) Quantification of POMC cell number and cell size in hypothalamic sections of $P$ tp $1 b^{+/+}$and Shp2 $2^{+/+}$(WT) compared with POMC-Ptp $1 b^{-/-}$and POMC-Shp2-/- (KO) mice; adult (3-8 months old) mice were analyzed, $n=3$ mice per genotype, $2-4$ sections per mouse. (E) Detection of deletion of $P t p 1 b$ or Shp2 alleles $(\Delta)$ in POMC-Ptp $1 b^{-/-}$and -Shp2 $2^{-/-}$mice compared with $P t p 1 b^{+/+}$and Shp2 $2^{+++}$controls. DNA was extracted from different tissues ( $P$, pituitary; $\mathrm{H}$, hypothalamus; B, whole brain; L, liver; K, kidney; F, fat; $M$, skeletal muscle; and hindbrain), and deletion of the floxed allele was detected by PCR. Recombination was detected only in pituitary, hypothalamus, whole brain, and hindbrain of POMC-Ptp $1 b^{-/-}$and -Shp2 $2^{-/-}$mice. A PCR reaction with IL-2 was used as an internal control. (F) PTP1B protein levels in Ptp $1 \mathrm{~b}^{+/+}$controls compared with POMC-Ptp $1 b^{-/-}$mice (top panels) and SHP2 protein levels in Shp2 ${ }^{+/+}$controls compared with POMC-Shp2-l- mice (bottom panels) as determined by immunoblotting. SHP2 and ERK2 protein levels, respectively, are shown as a loading control. Hypo, hypothalamus.

Hindbrain

WT KO

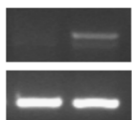

Hindbrain

WT KO

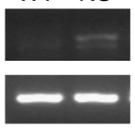

of the leptin receptor (LRb) in POMC neurons (POMC-Cre:Leprfox/flox) results in increased body weight and adiposity, hyperleptinemia, altered hypothalamic neuropeptide expression, and impaired glucose tolerance (31-33). Selective reexpression of LRb in POMC neurons in an LRb-deficient background results in a modest reduction in body weight and normalization of blood glucose (34). Consistent with these studies, mice with POMC-specific disruption of Socs3, a negative regulator of leptin signaling, have enhanced leptin sensitivity, resistance to diet-induced obesity, and improved glucose homeostasis (35). Collectively, these studies highlight the physiological relevance of leptin signaling in POMC neurons.

Mice with neuronal PTP1B deficiency are lean and insulin hypersensitive, whereas mice with neuronal SHP2 deficiency are obese and glucose intolerant. The precise neuronal population(s) mediating these effects are unknown. Here we demonstrate that POMC-specific PTP1B deficiency protects against diet-induced obesity, improves leptin and insulin sensitivity, and results in reduced diet-induced liver triglyceride (TG) accumulation. In contrast, POMC-specific SHP2 deficiency results in obesity, leptin resistance, elevated diet-induced liver TGs, and reduced hypothalamic Pomc mRNA and $\alpha \mathrm{MSH}$ 
A

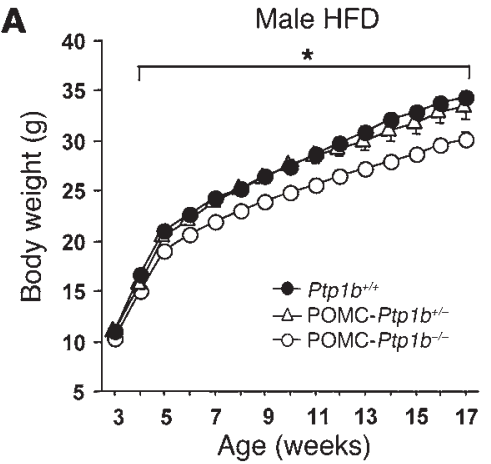

C

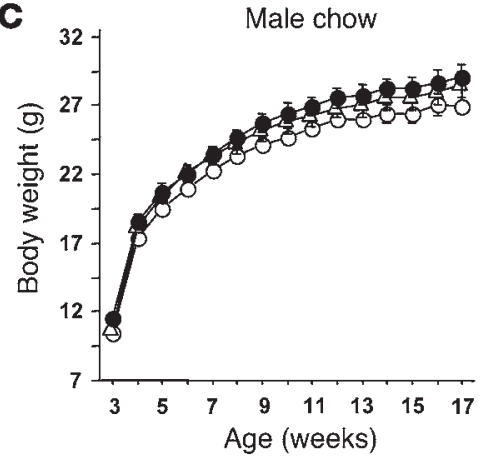

E

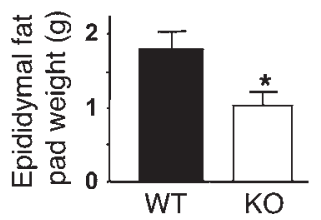

$\mathbf{F}$
B

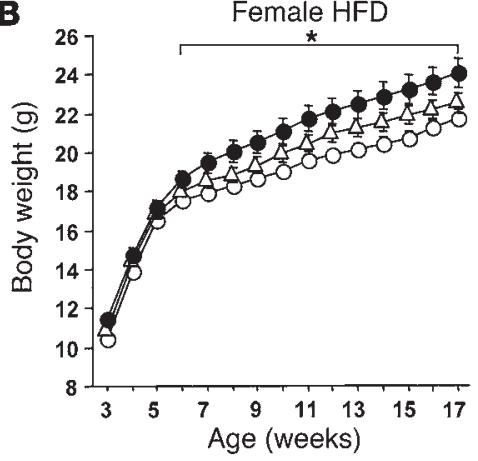

D

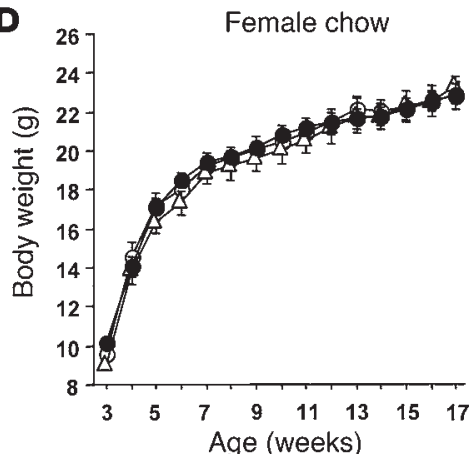

G

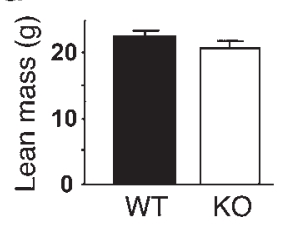

H

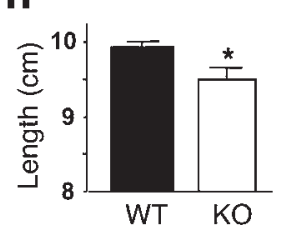

Figure 2

POMC-Ptp $1 b^{-/-}$mice are resistant to HFD-induced obesity. (A) Body weights of male POMC-Ptp $1 b^{-/-}(n=24)$ and -Ptp $1 b^{+/-}$mice $(n=27)$ and Ptp $1 b^{+/+}$controls $(n=31)$ on HFD. (B) Body weights of female POMC-Ptp $1 b^{-/-}(n=20)$ and -Ptp $1 b^{+/-}$mice $(n=21)$ and Ptp $1 b^{+/+}$controls $(n=24)$ on HFD. (C) Body weights of male POMC-Ptp $1 b^{-/-}(n=11)$ and -Ptp $1 b^{+/-}$mice $(n=10)$ and Ptp $1 b^{+/+}$controls $(n=10)$ on a chow diet. (D) Body weights of female POMC-Ptp $1 b^{-/-}(n=8)$ and $-P t p 1 b^{+/-}$mice $(n=6)$ and Ptp $1 b^{+/+}$ controls $(n=8)$ on a chow diet. (E) Male POMC-Ptp $1 b^{-/-}(\mathrm{KO})$ mice have decreased epididymal fat pad weight on HFD compared with Ptp1 $b^{+/+}$(WT) controls. (F) Male POMC-Ptp $1 b^{-/-}$mice have decreased fat mass on HFD as determined by DEXA. (G) Lean mass of male POMC-Ptp $1 b^{-/-}$and Ptp $1 b^{+/+}$control mice on HFD as determined by DEXA; for $\mathbf{E}-\mathbf{G}, n=8 /$ genotype, $17-18$ weeks of age. (H) Male POMC-Ptp $1 b^{-/-}$mice have decreased length compared with Ptp $1 b^{+/+}$controls on HFD ( $n=10 /$ group). All values are mean \pm SEM. ${ }^{*} P<0.05$ for POMC-Ptp $1 b^{-/-}$versus Ptp $1 b^{+/+}$controls by ANOVA ( $\mathbf{A}$ and $\mathbf{B}$ ) or 2-tailed Student's $t$ test $(\mathbf{E}-\mathbf{H})$. peptide. These studies point to a novel role for PTP1B and SHP2 in POMC neuron control of energy balance.

\section{Results}

Generation of POMC-specific Ptp $1 b^{-/-}$and $-S h p 2^{-/-}$mice. To generate POMC-specific PTP1B- and SHP2-deficient mice, we crossed Ptpn1 1oxP/loxP (19) and Ptpn11 loxP/loxP (36) mice to mice expressing Cre recombinase under the control of the POMC promoter (31) to generate Ptpn1 1/loxP POMC-Cre and Ptpn11//loxP POMC-Cre mice. Subsequently, we crossed these mice to $P t p^{l o x P} /$ loxP or $P t p^{+/ l o x P}$ mice to yield $P t p^{l o x P} /$ loxP POMC-Cre mice (hereafter termed POMC$P t p 1 b^{-/-}$and POMC-Shp $\left.2^{-/-}\right), P t p^{+/ l o x P}$ POMC-Cre mice (hereafter termed POMC-Ptp1 $1 b^{+/-}$and POMC-Shp2 $\left.2^{+-}\right)$, and Ptp loxP/loxP $\left(P t p 1 b^{+/+}\right.$and $\left.S h p 2^{+/+}\right)$"wild-type" littermate controls. Ptpn $1^{+/+}$ POMC-Cre mice were also generated during these crosses and served as Cre-only littermate controls.

To visualize POMC cell-specific Cre-mediated recombination, we crossed Ptpn $1^{\text {loxP/loxP }}$ POMC-Cre mice to mice of the $Z / E G$ reporter strain, which express EGFP only after Cre-mediated recombination. $P$ tpn $1^{\text {loxP/loxP}} ; \mathrm{POMC}-\mathrm{Cre} ; \mathrm{Z} / \mathrm{EG}$ mice expressed EGFP in the ARC in a pattern consistent with POMC neuron localization, whereas control Ptpn $1^{\text {loxP/loxP}} ; \mathrm{Z} / \mathrm{EG}$ mice did not express GFP (Figure 1A). No differences were found in the relative number or size of arcuate POMC neurons between colchicine-treated control and POMC-Ptp $1 b^{-/-}$mice or in control versus POMC-Shp2 $2^{-1-}$ mice (Figure 1, B-D).
Consistent with areas of endogenous POMC expression, deletion of the Ptp1b allele in POMC-Ptp1 $1 b^{-/-}$mice and the Shp2 allele in POMC-Shp2 $2^{-/-}$mice was only detected in DNA extracts from the hypothalamus, pituitary, and hindbrain (including the nucleus of the solitary tract [NTS]). No deletion of the floxed alleles was detected by PCR in $P t p 1 b^{+/+}$or $S h p 2^{+/+}$mice (Figure 1E). Immunoblot analyses showed no difference in PTP1B or SHP2 protein levels in lysates obtained from whole hypothalamus or peripheral tissues, which was expected, since POMC neurons make up only a very small fraction of the hypothalamus (Figure 1F).

POMC-Ptp $1 b^{-/-}$mice are resistant to diet-induced obesity. To assess whether energy balance is affected by POMC neuron PTP1B deficiency, we examined body weights and adiposity in mice placed on either a high-fat diet (HFD) or low-fat chow diet at weaning. Body weights of male POMC-Ptp $1 b^{-/-}$mice were significantly lower than those of POMC-Ptp $1 b^{+/-}$and $P t p 1 b^{+/+}$mice on HFD after 4 weeks of age (Figure 2A). Body weights of female POMC-Ptp $1 b^{-/-}$mice were significantly lower than those of $P t p 1 b^{+/+}$mice on HFD after 6 weeks of age, and female POMC-Ptp $1 b^{+/-}$mice show a trend toward lower body weights on HFD compared with $P t p 1 b^{+/+}$controls, although this did not reach statistical significance (Figure 2B). On a chow diet, male and female mice showed no significant differences in body weight between genotypes (Figure 2, C and D). POMC-Cre control mice and $P t p 1 b^{+/+}$mice gained comparable amounts of weight on HFD (see Supplemental Figure 1; supplemental material available online with this article; doi:10.1172/ 
A
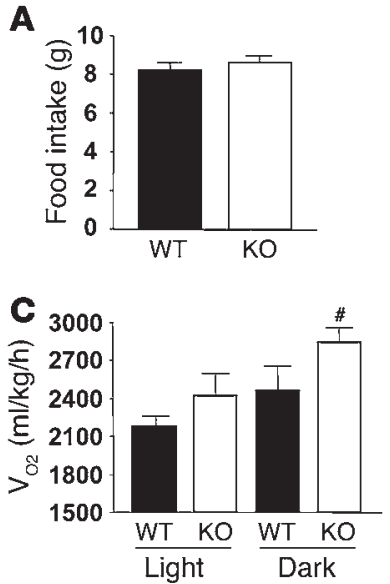

D

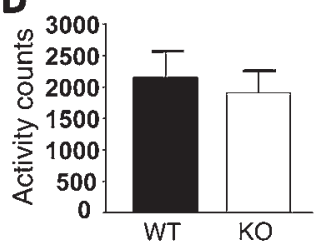

B
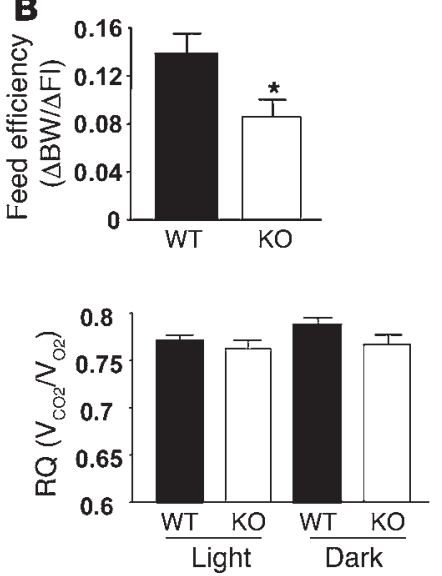

E

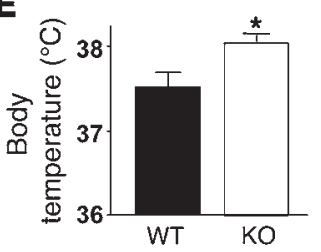

JCI39620DS1). Adiposity was decreased in male POMC-Ptp16-/mice on HFD, as evidenced by reduced epididymal fat pad weight (Figure 2E) and reduced percentage of fat mass as measured by dual energy X-ray absorptiometry (DEXA; Figure 2F). Similar results were obtained in female mice (data not shown). No significant differences were found in lean mass between POMC-Ptp1 $1 b^{-/-}$ and $P t p 1 b^{+/+}$controls (DEXA; Figure 2G), despite a small but reproducible reduction in body length of POMC-Ptp $1 b^{-/-}$mice on both diets (Figure $2 \mathrm{H}$, and data not shown). These results suggest that the decreased body weight of POMC-Ptp $1 b^{-/-}$mice on HFD is due primarily to a reduction in fat mass.

Energy expenditure is increased in POMC-Ptp $1 b^{-/-}$mice. To determine the cause of reduced weight/adiposity in POMC-Ptp $1 b^{-/-}$mice, we examined energy expenditure parameters when animals were maintained on HFD. Food intake was similar in POMC-Ptp $1 b^{-/-}$ and $P t p 1 b^{+/+}$control animals (Figure $3 \mathrm{~A}$ ), but feed efficiency $(\Delta \mathrm{BW} /$ $\Delta$ food intake) was significantly lower in POMC-Ptp $1 b^{-/-}$mice compared with $P t p 1 b^{+/+}$mice (Figure 3B). These results suggest that POMC-PTP1B deficiency results in increased energy expenditure. To assess energy expenditure directly, we monitored 17-week-old male mice on HFD in open-circuit indirect calorimetry cages. Oxygen consumption $\left(\mathrm{V}_{\mathrm{O} 2}\right)$ was elevated in POMC-Ptp $1 b^{-/-}$mice compared with $P t p 1 b^{+/+}$controls, particularly during the dark cycle, when mice are most active (Figure 3C). No differences between genotypes were noted in respiratory quotient (RQ) or in locomotor activity of male mice on HFD (Figure 3, C and D); however, the body temperature of POMC-Ptp $1 b^{-/-}$mice was elevated compared with that of controls (Figure $3 \mathrm{E}$ ). These results suggest that the decreased fat mass caused by POMC neuron PTP1B deficiency on HFD is due to increased energy expenditure.

Leptin sensitivity is enhanced in POMC-Ptp $1 b^{-/-}$mice. Mice with global or brain-specific PTP1B deletion are leptin hypersensitive (16, $17,19)$. In order to determine whether the increased energy expenditure seen in POMC-Ptp $1 b^{-/-}$mice was due to enhanced leptin sensitivity, we injected male mice on chow diet every 12 hours over

\section{Figure 3}

POMC-Ptp $1 b^{-/-}$mice have increased energy expenditure. (A) Cumulative food intake for 3 days on HFD at the age of 5-6 weeks $(n=8 /$ group). (B) POMC-Ptp $1 b^{-/-}$mice have decreased feed efficiency on HFD at the age of 6 weeks compared with Ptp $1 b^{+/+}$controls $(n=8 /$ group). FI, food intake. (C) POMC-Ptp $1 b^{-/-}$mice have increased energy expenditure as indicated by increased $\mathrm{V}_{\mathrm{O} 2}$ particularly during the dark cycle on HFD at the age of 17 weeks compared with Ptp $1 b^{+/+}$ controls ( $n=8 /$ group); no significant differences between genotypes were found in RQ values. (D) Locomotor activity of mice on HFD at the age of 17 weeks measured during the calorimetry experiment $(n=8 /$ group). (E) POMC-Ptp $1 b^{-/-}$mice have increased body temperature on HFD at the age of 10 weeks compared with Ptp $1 b^{+/+}$controls $(n=11 /$ group). All data were collected from male mice; WT, Ptp $1 b^{+/+}, \mathrm{KO}$, POMC-Ptp $1 b^{-/}$mice. All values are mean \pm SEM. ${ }^{*} P<0.05$ POMC$P$ tp $1 b^{-/-}$versus $P$ tp $1 b^{+/+}$controls by 2 -tailed Student's $t$ test, ${ }^{\#} P=0.06$ by 2 -tailed Student's $t$ test.

a 36-hour period with saline or a low dose of leptin $(0.5 \mu \mathrm{g} / \mathrm{g} /$ injection, i.p.). In response to leptin treatment, POMC-Ptp $1 b^{-/-}$mice showed suppression of food intake and decreased body weight, whereas $P t p 1 b^{+/+}$controls did not respond to this dose of leptin, demonstrating that POMC-Ptp $1 b^{-/}$mice are indeed more leptin sensitive than controls (Figure 4A). In addition, 12-week-old chowfed male POMC-Ptp $1 b^{-/-}$mice injected with a single dose of leptin (3 $\mu \mathrm{g} / \mathrm{g}$, i.p.) displayed a higher percentage of pStat3-positive POMC neurons compared with leptin-injected $P t p 1 b^{+/+}$littermate controls (Figure 4, B and C), indicating that leptin sensitivity is enhanced within PTP1B-deficient POMC neurons. Hypothalamic mRNA expression levels of Agrp, neuropeptide Y (Npy), and Pomc were similar in fed and fasted POMC-Ptp $1 b^{-/-}$and $P t p 1 b^{+/+}$mice on HFD (Supplemental Figure 2).

POMC-Shp $2^{-/-}$mice are sensitive to diet-induced obesity. To assess whether energy balance is affected by POMC neuron-specific SHP2 deficiency, body weights and adiposity were examined in mice maintained on HFD or chow diet at weaning. In contrast to the results in POMC-Ptp $1 b^{-/-}$mice, body weights of male and female POMC-Shp $2^{-/-}$mice were significantly higher than those of Shp $2^{+/+}$control mice on HFD (Figure 5, A and B). Furthermore, male and female POMC-Shp $2^{-/-}$mice weighed more than controls even on the low-fat chow diet (Figure 5, C and D). Consistent with their increased body weight, POMC-Shp $2^{-/-}$mice maintained on HFD had increased epididymal fat pad weight (Figure 5E) and increased fat mass (DEXA; Figure 5F). No differences were found in lean mass of POMC-Shp2 $2^{-1-}$ mice compared with littermate controls by DEXA analysis, despite the fact that they were slightly longer than control mice (Figure 5, G and $\mathrm{H}$ ).

To determine the cause of elevated body weight/adiposity in POMC-Shp $2^{-/-}$mice, we examined energy expenditure parameters on HFD. Food intake was similar in POMC-Shp $2^{-/-}$and $S h p 2^{+/+}$control animals (Figure 6A), but feed efficiency was significantly higher in POMC-Shp $2^{-/-}$mice compared with $S h p 2^{+/+}$controls (Figure $6 \mathrm{~B})$, suggesting that POMC-SHP2 deficiency results in decreased energy expenditure. Direct assessment of energy expenditure by indirect calorimetry showed a significant decrease in oxygen consumption in HFD-fed POMC-Shp $2^{-/-}$mice during both the light and dark cycles, as well as an overall decrease in RQ in the dark cycle compared with controls (Figure 6C). Locomotor activity of POMC-Shp2 $2^{-/-}$mice was also reduced (Figure 6D).

Leptin sensitivity is impaired in POMC-Shp $2^{-1-}$ mice. In order to determine the cause of the increased body weight and reduced energy 

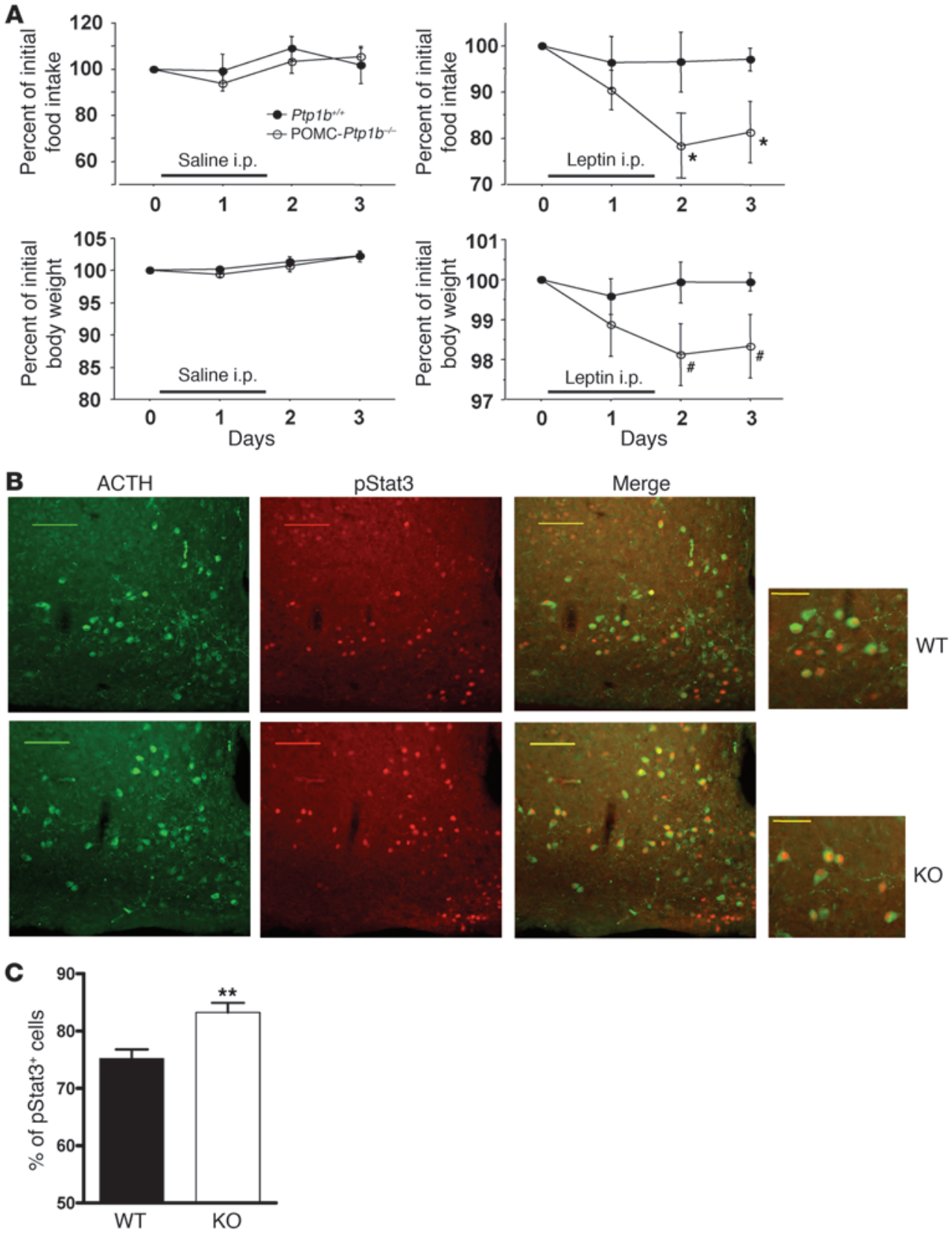

expenditure in POMC-Shp $2^{-/-}$mice, we examined in vivo leptin sensitivity. Consistent with previous studies showing that mice with neuronal deletion of SHP2 are leptin resistant $(27,28)$, we found that weight-matched male POMC-Shp $2^{-1-}$ mice on chow diet were resistant to the effects of a higher dose of leptin $(2.0 \mu \mathrm{g} / \mathrm{g} /$ injection, i.p.) that caused a reduction in food intake and body weight of weight-matched Shp2 $2^{+/+}$controls (Figure 7A). Saline injections over the same time period did not affect body weight or food intake in any of the groups (Figure 7A). Consistent with chronic leptin resistance, POMC-Shp $2^{-/-}$mice had decreased hypothalamic Pomc mRNA expression on HFD in both the fed and fasted states (Figure 7B); no significant changes were observed in Npy or Agrp mRNA expression (Figure 7, C and D).

Metabolic parameters in POMC-Ptp $1 b^{-/-}$and $-S h p 2^{-/-}$mice. POMCPTP1B deficiency resulted in reduced blood glucose and serum insulin levels, decreased serum leptin levels, and improved serum TGs in male mice on HFD for 15 weeks (Table 1). No differences between genotypes were noted in these parameters on a chow diet. Serum FFA levels were similar between genotypes on both diets. Interestingly, serum adiponectin levels were significantly higher in POMC-Ptp $1 b^{-/-}$mice compared with $P t p 1 b^{+/+}$controls on a chow diet (Table 1). Since adiponectin levels positively correlate with insulin sensitivity (37-39), these data suggest that mice lacking PTP1B in POMC neurons may have increased peripheral insulin sensitivity even on the low-fat chow diet. In contrast to the results in POMC-Ptp $1 b^{-/-}$mice, deletion of SHP2 in POMC neurons led to elevated fed serum insulin levels and insulin/glucose ratio, as well as increased serum leptin and TG levels on HFD (Table 2). Leptin levels were also elevated in POMC-Shp $2^{-/-}$mice on a chow diet, while serum FFA and serum adiponectin levels were not dif- 
A
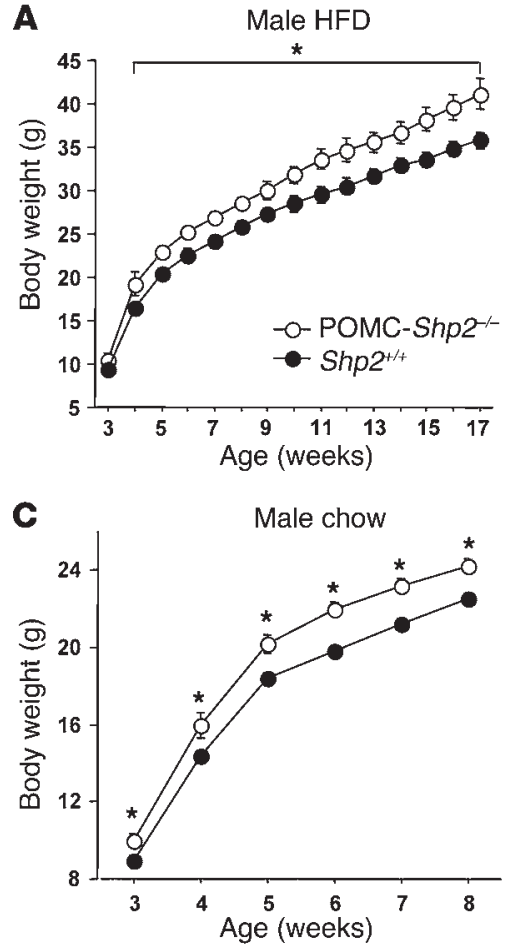

B

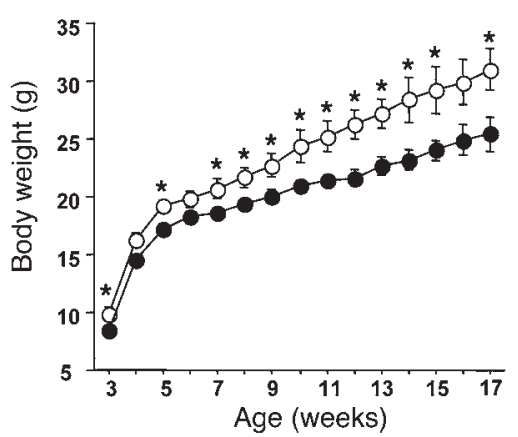

D

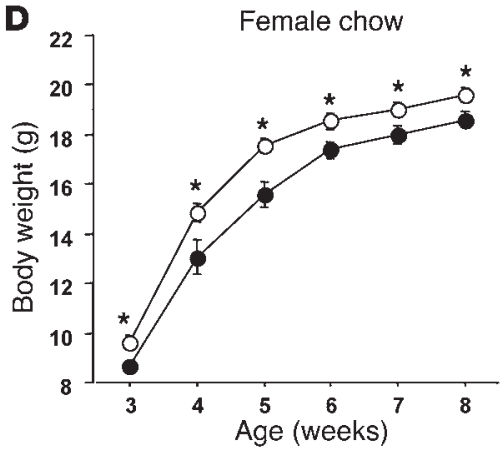

\section{Figure 5}

POMC-Shp2-/- mice are sensitive to HFDinduced obesity. (A) Body weights of male POMC-Shp2-/- mice $(n=8)$ versus Shp2+/+ controls $(n=11)$ on HFD. (B) Body weights of female POMC-Shp2--/ mice $(n=7)$ versus Shp2 $2^{+/+}$controls $(n=6)$ on HFD. (C) Body weights of male POMC-Shp2 $2^{--}$mice $(n=15)$ versus Shp $2^{+/+}$controls $(n=21)$ on a chow diet. (D) Body weights of female POMC-Shp2-/mice $(n=17)$ versus Shp2 $2^{++}$controls $(n=14)$ on a chow diet. (E) Male POMC-Shp2--- (KO) mice have increased epididymal fat pad weight compared with Shp2+/+ (WT) mice on HFD. (F) Male POMC-Shp2-- mice have increased fat mass on HFD as determined by DEXA of abdomen. (G) Lean mass of males on HFD as determined by DEXA. For E-G, $n=8 /$ genotype, $17-18$ weeks of age. (H) Male POMC-Shp2--- mice have increased length compared with Shp2+/+ controls ( $n=10 /$ genotype). All values are mean $\pm \mathrm{SEM}$. ${ }^{*} P<0.05$, POMC-Shp2 $2^{-/-}$versus Shp2+/+ controls by 2-tailed Student's $t$ test.
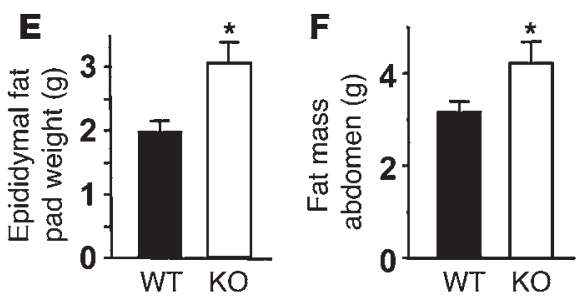

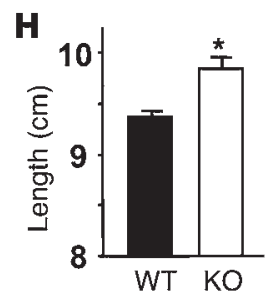

ferent between genotypes (Table 2). No differences were found in serum corticosterone levels in mice with POMC-PTP1B or -SHP2 deficiency compared with littermate controls (Tables 1 and 2).

Deletion of PTP1B or SHP2 in POMC neurons has a reciprocal effect on $H F D$-induced hepatic steatosis. High-fat feeding results in increased accumulation of TG in the liver and causes hepatic steatosis (40). Intracerebroventricular leptin has been shown to suppress expression of the lipogenic gene stearoyl-coenzyme A desaturase-1 (Scd1) and improve fatty liver of lipodystrophic mice, suggesting that the antisteatotic effects of leptin may be mediated centrally (41). Given the lipid-lowering role of leptin in vivo, we analyzed lipid content of livers from HFD-fed POMC-Ptp $1 b^{-/-}$mice and POMC$S h p 2^{-/-}$mice. Hepatic TG content was reduced in POMC-Ptp $1 b^{-/-}$ mice compared with controls after prolonged high-fat feeding (15 weeks on HFD; Table 1). Expression of the lipogenic genes Scd1 and peroxisome proliferator-activated receptor gamma 2 (Pparg2) was decreased in livers of POMC-Ptp $1 b^{-/-}$mice compared with $P t p 1 b^{+/+}$controls (Table 1). In contrast, POMC-Shp $2^{-/-}$mice had increased hepatic TG content and elevated expression of Scd1 and Pparg2 mRNA in the liver (Table 2).

$\alpha M S H$ projections in POMC-Ptp $1 b^{-/-}$and $-S h p 2^{-/-}$mice. To further investigate the mechanism of altered energy balance in POMC$P t p 1 b^{-/-}$and POMC-Shp $2^{-/-}$mice, we examined $\alpha \mathrm{MSH}$ peptide content in efferent fibers of the PVN. Young (5- to 6-week-old) female POMC-Ptp $1 b^{-/-}$and $P t p 1 b^{+/+}$mice on a chow diet showed comparable $\alpha \mathrm{MSH}$-immunolabeled efferent fibers innervating the PVN (Figure 8, A and B). In contrast, 5- to 6-week-old female POMC-Shp $2^{-1-}$ mice had significantly reduced $\alpha \mathrm{MSH}$ immunolabeling of fibers in the PVN (and in the DMH; data not shown) compared with Shp $2^{+/+}$controls (Figure 8, A and B). Consistent with these data, POMC-Ptp $1 b^{-/-}$mice had similar levels of hypothalamic $\alpha \mathrm{MSH}$ peptide levels compared with $P t p 1 b^{+/+}$littermate controls, whereas POMC-Shp2-/- mice had substantially reduced $\alpha \mathrm{MSH}$ peptide levels compared with $S h p 2^{+/+}$controls (Figure $8 \mathrm{C}$ ). Thus, although POMC-SHP2 deficiency does not appear to alter the morphology or number of ARC POMC neurons (Figure 1D), it resulted in significantly reduced hypothalamic Pomc mRNA and reduced $\alpha \mathrm{MSH}$ peptide levels in important target hypothalamic nuclei innervated by POMC neurons. The overall reduced activity of the melanocortin system in POMC-Shp $2^{-/-}$mice provides a likely mechanism for the increased body weight.

Glucose homeostasis in POMC-Ptp1 $1 b^{-/-}$and $-S h p 2^{-/-}$mice. To evaluate the effects of POMC-PTP1B deficiency on peripheral glucose homeostasis, we performed glucose tolerance tests (GTTs) and insulin tolerance tests (ITTs) on male POMC-Ptp $1 b^{-/-}$mice and littermate controls. In mice on HFD, POMC-PTP1B deficiency resulted in improved glucose tolerance and enhanced insulin sensitivity compared with controls (Figure 9, A and B). On a chow 
A
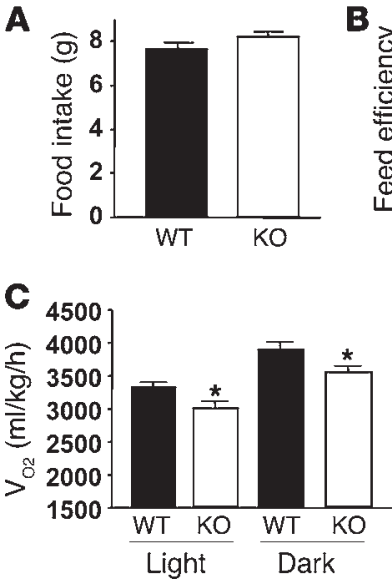

D

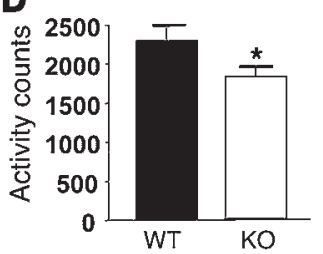

diet, there were no statistically significant differences between POMC-Ptp $1 b^{-/-}$and $P t p 1 b^{+/+}$mice in the GTT, whereas POMC$P t p 1 b^{-/}$mice showed improved insulin sensitivity compared with controls as measured by ITT (Figure 9, C and D). The improved insulin sensitivity in POMC-Ptp $1 b^{-/}$mice seen by ITT, along with increased adiponectin levels, suggest that insulin sensitivity is improved in POMC-Ptp $1 b^{-/-}$mice on a chow diet despite the fact that there was no difference in body weight between POMC-Ptp $1 b^{-/-}$and $P t p 1 b^{+/+}$mice. To assess insulin sensitivity in mice on a chow diet more precisely, we subjected male POMC$P t p 1 b^{-/-}$and $P_{t p} 1 b^{+/+}$littermate control mice to hyperinsulinemiceuglycemic clamp analysis. There were no significant differences in body weight, fat pad weight, or basal blood glucose levels between POMC-Ptp $1 b^{-/-}$and $P t p 1 b^{+/+}$mice on a chow diet (Figure $9, \mathrm{E}-\mathrm{G})$. During the clamp, POMC-Ptp $1 b^{-/-}$mice had an increased glucose infusion rate (GIR) (Figure $9 \mathrm{H}$ ) and enhanced suppression of hepatic glucose production (HGP) (Figure 9I). The rate of insulin-stimulated glucose disappearance (Rd) was increased in POMC-Ptp $1 b^{-/-}$mice compared with controls (Figure 9J), indicating an overall increase in insulin sensitivity.

POMC-SHP2 deficiency led to impaired glucose tolerance and insulin sensitivity on a chow diet (Supplemental Figure 3, A and B). Since these mice had differences in body weight and adiposity at the time of analysis, however, it is difficult to determine whether the impairment in insulin sensitivity was secondary to increased fat mass in POMC-Shp2 $2^{-1-}$ mice. To determine the effects of POMC-SHP2 deficiency on glucose homeostasis independent of changes in body weight and adiposity, we matched male POMC$S h p 2^{-/-}$and $S h p 2^{+/+}$mice for body weight and percentage fat mass by NMR (Supplemental Figure 3, C and D) and subjected them to hyperinsulinemic-euglycemic clamp analysis. No differences were found between genotypes in blood glucose levels, GIR, HGP, or Rd (Supplemental Figure 3, E-H), suggesting that impairment in insulin and glucose tolerance on a chow diet is secondary to the elevated body weight and fat mass in POMC-Shp $2^{---}$mice.

\section{Figure 6}

POMC-Shp2 $2^{-/-}$mice have decreased energy expenditure. (A) Cumulative food intake for 3 days on HFD at the age of 11 weeks $(n=7$ / group). (B) POMC-Shp2-l- mice have increased feed efficiency on HFD compared with Shp2 ${ }^{+/+}$controls (11 weeks old; $n=7 /$ group). (C) POMC-Shp2 $2^{--}$mice have decreased energy expenditure on HFD compared with $S h p 2^{+/+}$controls as indicated by decreased $\mathrm{V}_{\mathrm{O} 2}$ during both the light and dark cycles; POMC-Shp2 ${ }^{-/-}$mice show decreased $\mathrm{RQ}$ during the dark cycle compared with $S h p 2^{+/+}$controls (14 weeks old; $n=8$ /group). (D) Locomotor activity of POMC-Shp2-l- mice is decreased on HFD (14 weeks old; $n=8 /$ group). All data were collected from male mice; WT, Shp2 $2^{++}$; KO, POMC-Shp2 $2^{-/}$mice. All values are mean \pm SEM. ${ }^{*} P<0.05$, POMC-Shp2 ${ }^{-/-}$versus Shp $2^{+/+}$ controls by 2 -tailed Student's $t$ test.

\section{Discussion}

To investigate the specific neuronal population(s) mediating alterations in energy balance and glucose homeostasis in brain-specific PTP1B- and SHP2-deficient mice, we generated mice with POMC neuron disruption of PTP1B or SHP2. Our data highlight an important reciprocal role for PTP1B and SHP2 in POMC neuron control of HFD-induced weight gain, energy expenditure, leptin and insulin sensitivity, and hepatic steatosis.

Leptin acts through LRb, which is highly expressed in the ARC, and in other localized areas throughout the brain (42-44). Leptin binding to LRb causes autophosphorylation and activation of associated Jak2, which in turn phosphorylates critical tyrosine residues on the intracellular domain of the LRb, including $\mathrm{Y}^{985}$ and $\mathrm{Y}^{1138}$ (reviewed in refs. 45-49). Phosphorylated tyrosine residues on the $\mathrm{LRb}$ provide docking sites for downstream signaling molecules, including Stat3 and suppressor of cytokine signaling (Socs3), a feedback inhibitor of leptin signaling. PTP1B acts as a negative regulator of leptin signaling by directly dephosphorylating Jak2 (16-18). In contrast, SHP2 is thought to promote leptin signaling. Tyrosine phosphorylation of $\mathrm{Y}^{985}$ recruits SHP2, which competes for binding with Socs 3 and mediates leptin activation of the growth factor receptor-bound protein 2 (Grb2)/ERK pathway (25). In vivo studies have implicated both PTP1B and SHP2 in regulation of leptin signaling and whole body energy balance $(16,17,19,27)$.

The expression of PTP1B is induced in the hypothalamus of mice in response to high-fat feeding, and PTP1B deficiency in the brain results in decreased body weight and improved leptin sensitivity $(16,17,19,50,51)$. However, the role(s) played by PTP1B in specific neurons that control energy balance remains unknown. We find that POMC-Ptp $1 b^{-/-}$mice weigh less than wild-type controls on HFD due to decreased adiposity and increased energy expenditure, implicating POMC neurons as an important site of PTP1B action. Whether altered metabolism in POMC-Ptp $1 b^{-/-}$mice is due to enhanced neuronal leptin signaling or other signaling pathways affected by PTP1B deletion is currently unknown. While our data demonstrate improved leptin sensitivity in the absence of PTP1B (including enhanced leptin-stimulated pStat3 within PTP1B-deficient POMC neurons themselves), PTP1B has been implicated in the regulation of other signaling pathways that may regulate energy balance, including insulin and cytokine signaling $(52,53)$.

Insulin has been shown to have central effects on body weight, hepatic glucose production, and hepatic Stat3 activation (54-59). Genetic disruption of IR expression in the CNS leads to obesity and peripheral insulin resistance in mice (57), and insulin injection directly in the mediobasal hypothalamus improves hepatic insulin 

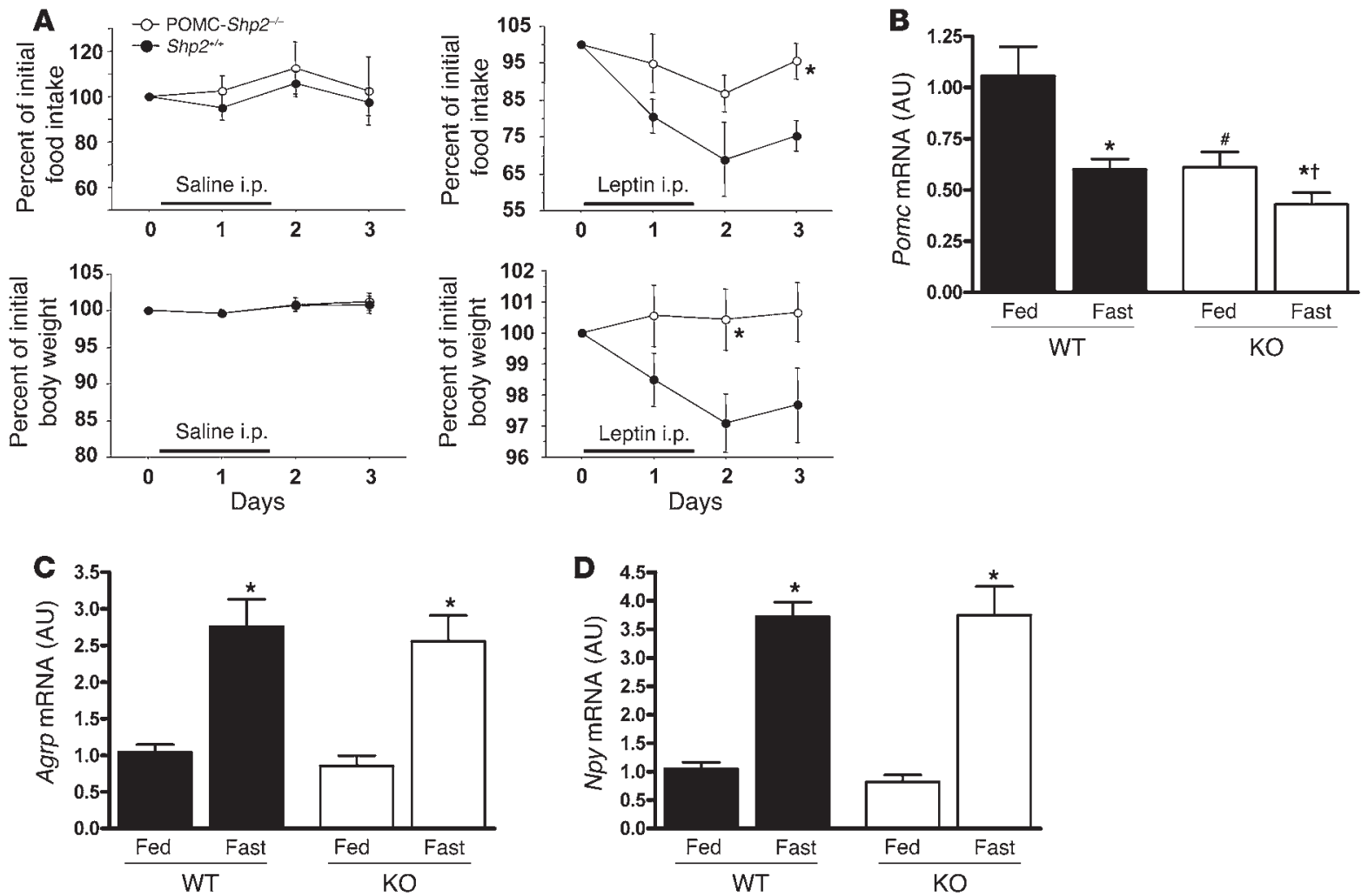

Figure 7

Leptin sensitivity is impaired in POMC-Shp2-/- mice. (A) Weight-matched male mice (8-10 weeks of age on chow diet) were selected for this experiment from a large cohort of mice to control for body weight differences. Mice were injected with leptin every 12 hours $(2 \mu \mathrm{g} / \mathrm{g}$ BW/injection) or saline i.p. during the indicated period. Shp2 ${ }^{+/+}$controls show a greater suppression of food intake and body weight than POMC-Shp2 $2^{-/-}$mice ( $n=6 /$ group leptin; $n=3-5$ saline controls). Food intake and body weight were measured for 2 days prior to the start of injections and normalized to $100 \%$ for day 0 values. All values are mean \pm SEM. ${ }^{*} P<0.05$, POMC-Shp2 ${ }^{-/-}$versus Shp2 $2^{+/+}$controls by 2 -tailed Student's $t$ test. (B) Consistent with impaired leptin sensitivity, hypothalamic expression of Pomc mRNA is reduced in both the fed and fasted states in POMC-Shp2 ${ }^{-/-}$mice (KO) versus Shp2+/+ controls (WT). Hypothalamic expression of both Agrp mRNA (C) and Npy mRNA (D) is similar in POMC-Shp2-/- mice and $\mathrm{Shp} 2^{+/+}$controls. All mice were males in either the fed state or 24-hour fasted state and on HFD for 14-16 weeks; $n=6-8$ per genotype. All values are mean \pm SEM. ${ }^{*} P<0.05$, fed versus fasted within genotype; ${ }^{P} P<0.05$, WT fed versus KO fed; ${ }^{\dagger} P<0.05$, WT fasted versus KO fasted, by 2 -tailed Student's $t$ test.

sensitivity in rats (55). Furthermore, insulin delivered to the third ventricle in rats causes upregulation of $\alpha \mathrm{MSH}$ expression and a reduction in food intake that is blocked in the presence of a melanocortin antagonist (60). Within the CNS, inhibitors of PI3K, a downstream mediator of multiple signaling pathways including insulin, have been shown to block the anorexigenic effects of insulin (61). In POMC neurons, insulin potently activates PI3K activity (62), but surprisingly, constitutive elevation of PIP3 within POMC neurons results in sex-specific hyperphagia and diet-induced obesity due to increased $\mathrm{K}_{\mathrm{ATP}}$ channel conductance (63). Notably, however, deletion of IR or IRS2 specifically in POMC neurons does not result in altered energy balance or glucose homeostasis on a chow diet or $\operatorname{HFD}(64,65)$, suggesting that PTP1B regulation of this pathway in POMC neurons is not likely to produce the observed phenotypes. PTP1B deficiency could in theory affect other cytokine-mediated signaling pathways, such as IL-6 (66) or gp130 signaling (67); however, there is no evidence currently implicating regulation of these pathways by PTP1B in hypothalamic neurons.

Previous reports demonstrated that mice with neuronal disruption of SHP2 are obese and leptin- and insulin-resistant $(27,28)$, but the neurons mediating these effects are unknown. We found that POMC-Shp $2^{-/-}$mice weighed more than littermate controls not only on HFD, but also on a chow diet. The response to exogenous leptin was blunted in these animals, and energy expenditure was reduced, consistent with the development of leptin resistance. Examination of $\alpha \mathrm{MSH}$-containing fiber projections in 5- to 6-week-old POMC-Shp $2^{-/-}$mice revealed a significant reduction in $\alpha \mathrm{MSH}$ immunolabeling in the PVN (Figure 8) and DMH (data not shown), as well as an overall reduction in hypothalamic $\alpha \mathrm{MSH}$ peptide content, raising the intriguing possibility that SHP2 may be important for the normal development of the hypothalamic melanocortin system. Since we stained for the $\alpha \mathrm{MSH}$ peptide directly, we cannot determine whether POMC-Shp $2^{-/-}$mice have impaired development of neuronal projections and/or simply have reduced $\alpha \mathrm{MSH}$ peptide content. It is interesting to note, however, that leptin has been shown to directly act on ARC neurons to stimulate axonal growth $(68,69)$ and is a critical trophic factor particularly during neonatal development of the hypothalamus (70). Orexigenic (NPY/AgRP) and anorexigenic (POMC) projections from the ARC to other hypothalamic nuclei, including PVN, 
Table 1

Metabolic parameters in POMC-Ptp1 $1 b^{-/}$mice on a chow diet or HFD

\begin{tabular}{|c|c|c|c|c|}
\hline & \multicolumn{2}{|c|}{ Chow diet } & \multicolumn{2}{|c|}{ HFD } \\
\hline & Ptp1 $b^{+/+}$ & POMC-Ptp1b-/- & Ptp1b $b^{+/+}$ & POMC-Ptp1b-/- \\
\hline Blood glucose (mg/dl) & $126.3 \pm 5.4$ & $116.4 \pm 7.4$ & $145.8 \pm 4.5$ & $126.5 \pm 7.0^{\mathrm{A}}$ \\
\hline Serum insulin (ng/ml) & $0.63 \pm 0.15$ & $0.61 \pm 0.04$ & $3.24 \pm 0.43$ & $1.90 \pm 0.19 \mathrm{~A}$ \\
\hline Insulin/glucose ratio & $0.005 \pm 0.001$ & $0.005 \pm 0.001$ & $0.023 \pm 0.004$ & $0.015 \pm 0.001^{B}$ \\
\hline Serum FFA (mM) & $0.354 \pm 0.043$ & $0.278 \pm 0.033$ & $0.609 \pm 0.113$ & $0.431 \pm 0.080$ \\
\hline Serum TG $(\mu \mathrm{g} / \mathrm{ml})$ & $285.91 \pm 33.23$ & $247.83 \pm 37.25$ & $406.24 \pm 40.02$ & $310.15 \pm 13.49^{A}$ \\
\hline Serum leptin (ng/ml) & $4.89 \pm 0.92$ & $3.45 \pm 0.44$ & $21.68 \pm 4.01$ & $10.17 \pm 2.22^{A}$ \\
\hline Serum adiponectin (ng/ml) & $9.54 \pm 2.17$ & $16.52 \pm 2.48^{A}$ & Not determined & Not determined \\
\hline Serum corticosterone (ng/ml) & $32.9 \pm 2.11$ & $38.01 \pm 1.90$ & Not determined & Not determined \\
\hline TG content in liver (mg/g) & Not determined & Not determined & $6.546 \pm 0.661$ & $4.575 \pm 0.541^{A}$ \\
\hline Scd1 mRNA (AU) & Not determined & Not determined & $1.011 \pm 0.250$ & $0.295 \pm 0.026^{A}$ \\
\hline Pparg2 mRNA (AU) & Not determined & Not determined & $1.078 \pm 0.184$ & $0.618 \pm 0.109 \mathrm{~A}$ \\
\hline
\end{tabular}

All data are from 17- to 18-week-old male mice ( $n=6-9$ per group). Data are expressed as mean \pm SEM.

${ }^{A} P<0.05,{ }^{B} P=0.06$ for POMC-Ptp $1 b^{-/}$mice versus $P t p 1 b^{+/+}$controls by 2 -tailed Student's $t$ test. possibility that defects in an Src kinase-dependent pathway could alter efferent projections in POMC-Shp2 $2^{-1-}$ mice. SHP2 also mediates signaling by the c-Ret receptor tyrosine kinase $(79,80)$, which has been shown to be important for normal axon growth and guidance in developing sympathetic neurons (81). Furthermore, NGFstimulated axonal growth is mediated via an SHP2-dependent mechanism in mouse sympathetic neurons (82). Collectively these studies highlight the potential complexity of SHP2 function in mediating neuronal development. More studies are needed to deter-
$\mathrm{DMH}$, and LHA, are severely impaired in $o b / o b$ mice, leptin receptor-deficient Zucker rats, and diet-induced obese rats $(68,70,71)$. Since reduced $\alpha \mathrm{MSH}$ fiber staining is observed in young (5- to 6-week-old) POMC-Shp $2^{-/-}$mice, this is unlikely to be secondary to the development of chronic, long-term leptin resistance.

Given the role SHP2 plays in multiple signal transduction pathways, it is difficult to attribute the observed phenotypes of POMC-Shp $2^{-/-}$mice to a particular signaling pathway. Multiple studies both in vitro and in vivo support a role for SHP2 as a positive mediator of leptin signaling at the cellular level, likely stemming from the $\mathrm{Y}^{985}$ site on the leptin receptor (25-28). It is plausible that impairments in leptin signaling in POMC-Shp $2^{-/-}$mice could lead to the phenotypes of these animals. However, it should be noted that mice with a homozygous mutation in $\mathrm{Y}^{985}(\mathrm{l} / \mathrm{l}$ mice) are not obese. In fact, female animals harboring this mutation are leaner than controls (72). The differences between POMC$S h p 2^{-/-}$mice and $l / l$ mice could be due to the fact that in POMCShp $2^{-/-}$mice, the $\mathrm{Y}^{985}$ site remains intact and available for Socs3 to bind without competition, thereby promoting negative regulation of leptin signaling. Alternatively, SHP2 may be regulating additional, unidentified signaling pathways in these neurons.

In addition to its regulation of leptin signaling, SHP2 is required for transduction of signals stemming from many other cell surface receptors, including the receptor tyrosine kinases EGF, FGF, PDGF, insulin, and nerve growth factor (NGF). SHP2 also promotes integrin signaling and Src family kinase activation (23, 52, 73-75). The Src family kinases Src and Fyn are highly expressed in the developing nervous system and localize to growth cones $(76,77)$. Mice lacking these tyrosine kinases have defects in axon outgrowth and guidance (78), raising the

\section{Table 2}

mine whether the observed phenotypes of the POMC-Shp $2^{-/-}$mice are due to impaired neuropeptide expression, development of neural projections, and/or defects in cellular signaling.

POMC-Ptp $1 b^{-/-}$mice have improved leptin sensitivity, whereas POMC-Shp $2^{-/-}$mice have impaired leptin sensitivity. Interestingly, while energy expenditure was altered in both lines of mice, food intake was not significantly affected by POMC deficiency of either PTP1B or SHP2. Mice with widespread neuronal SHP2 deficiency also showed altered energy expenditure, with no significant effect on food intake (27), whereas mice with neuronal deficiency of PTP1B displayed both increased energy expenditure and suppression of food intake (19). These data collectively suggest that PTP1B has an important role in $\mathrm{POMC}$ neuron regulation of energy expenditure, whereas non-POMC neurons likely mediate the intake-suppressive effects seen in brain-specific $P t p 1 b^{-/-}$mice. This idea is supported by an increasing number of studies showing that leptin acts at distributed sites across the CNS $(42,44,83,84)$. Consistent with their increased energy expenditure as measured by indirect calorimetry, POMC-Ptp $1 b^{-/-}$mice had elevated body temperature. However, POMC-Ptp $1 b^{-/-}$mice did not display altered locomotor activity.

Metabolic parameters in POMC-Shp2--- mice on a chow diet or HFD

\begin{tabular}{lcccc} 
& \multicolumn{2}{c}{ Chow diet } & \multicolumn{2}{c}{ HFD } \\
& Shp2 $2^{+/+}$ & POMC-Shp2 & Shp2 $2^{+/+}$ & POMC-Shp2-- \\
Blood glucose $(\mathrm{mg} / \mathrm{dl})$ & $124.6 \pm 4.3$ & $132.1 \pm 6.9$ & $151.6 \pm 8.5$ & $194.7 \pm 21.4$ \\
Serum insulin $(\mathrm{ng} / \mathrm{ml})$ & $0.61 \pm 0.09$ & $0.60 \pm 0.06$ & $2.05 \pm 0.26$ & $7.56 \pm 2.23^{\mathrm{A}}$ \\
Insulin/glucose ratio & $0.005 \pm 0.001$ & $0.005 \pm 0.0004$ & $0.013 \pm 0.003$ & $0.050 \pm 0.013^{\mathrm{B}}$ \\
Serum FFA $(\mathrm{mM})$ & $0.350 \pm 0.057$ & $0.339 \pm 0.038$ & $0.600 \pm 0.031$ & $0.637 \pm 0.027$ \\
Serum TG $(\mu \mathrm{g} / \mathrm{ml})$ & $285.17 \pm 33.99$ & $327.48 \pm 45.65$ & $424.84 \pm 82.94$ & $660.08 \pm 57.20^{\mathrm{A}}$ \\
Serum leptin $(\mathrm{ng} / \mathrm{ml})$ & $4.78 \pm 0.37$ & $6.08 \pm 0.45^{\mathrm{A}}$ & $21.10 \pm 1.96$ & $40.64 \pm 7.73^{\mathrm{A}}$ \\
Serum adiponectin $(\mathrm{ng} / \mathrm{ml})$ & $10.72 \pm 0.77$ & $11.67 \pm 0.61$ & Not determined & Not determined \\
Serum corticosterone $(\mathrm{ng} / \mathrm{ml})$ & $34.3 \pm 6.2$ & $29.1 \pm 9.1$ & Not determined & Not determined \\
TG content in liver $(\mathrm{mg} / \mathrm{g})$ & Not determined & Not determined & $9.821 \pm 0.999$ & $14.388 \pm 1.489^{\mathrm{A}}$ \\
Scd1 mRNA $(\mathrm{AU})$ & Not determined & Not determined & $0.946 \pm 0.094$ & $2.369 \pm 0.720^{\mathrm{C}}$ \\
Pparg2 mRNA $(\mathrm{AU})$ & Not determined & Not determined & $1.075 \pm 0.188$ & $1.854 \pm 0.274^{\mathrm{A}}$
\end{tabular}

All data are from 17- to 18-week-old male mice ( $n=6-9$ per group). Data are expressed as mean \pm SEM.

${ }^{\mathrm{A}} P<0.05,{ }^{\mathrm{B}} P=0.06,{ }^{\mathrm{C}} P=0.07$, POMC-Shp $2^{-/-}$mice versus Shp $2^{+/+}$controls by 2 -tailed Student's $t$ test. 
A
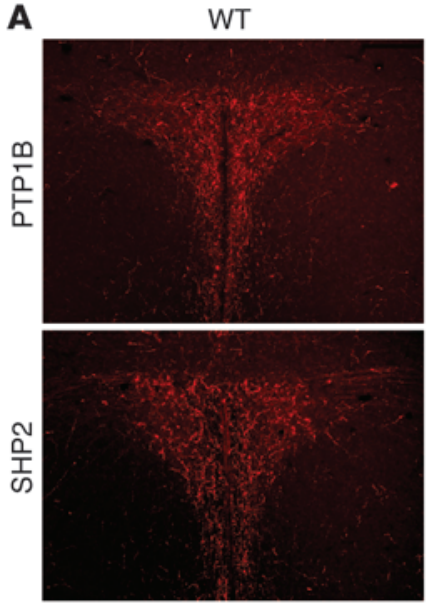

B

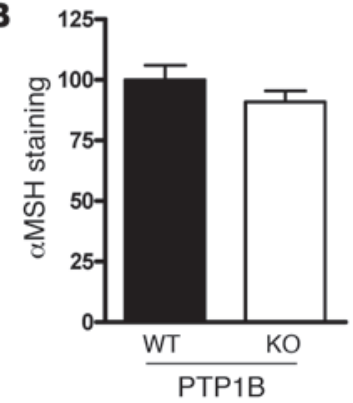

KO
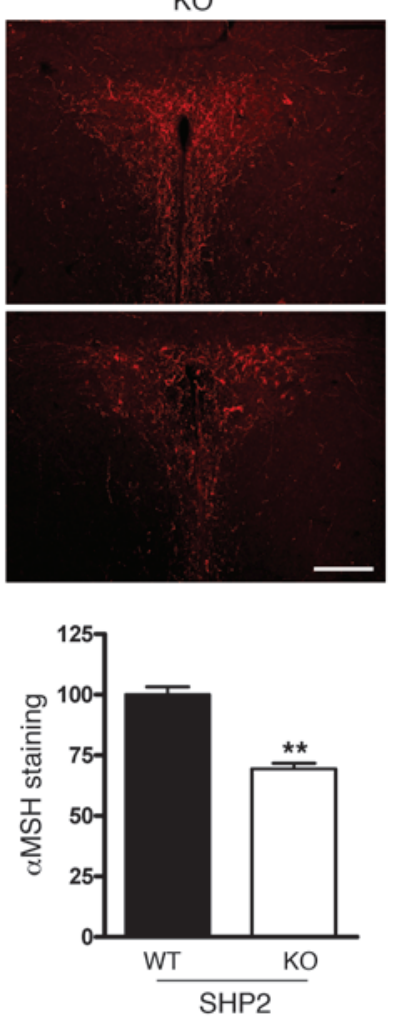

This finding is in contrast to the increased locomotor activity seen in whole-brain $P t p 1 b^{-/-}$mice, suggesting that this also may be due to deletion of PTP1B in non-POMC neurons.

Mice with PTP1B deficiency in brain, muscle, and liver all show improvements in peripheral insulin sensitivity (19-21). Here we found that POMC-Ptp1 $1 b^{-/-}$mice had improved insulin sensitivity on a low-fat chow diet in the absence of a weight difference (and similar adiposity compared with controls). These data suggest that PTP1B may regulate a neural pathway that can directly influence peripheral insulin sensitivity under physiological conditions. Other studies are consistent with the idea that CNS pathways can regulate glucose homeostasis (reviewed in refs. 85, 86). For example, insulin action in AgRP neurons is required for the insulin-induced suppression of hepatic glucose production (64), and hypothalamic lipid sensing can modulate glucose metabolism in the liver via a direct brain-liver circuit (87). Furthermore, mice expressing a mutant Kir6.2 subunit in POMC neurons have disrupted glucose sensing and impaired systemic glucose tolerance

\section{Figure 8}

aMSH peptide levels in the PVN of POMC-Ptp $1 b^{-/-}$and $-S h p 2^{-/-}$mice. (A) $\alpha \mathrm{MSH}$ staining of hypothalamic projections to the PVN of 5- to 6-week-old female POMC-Ptp $1 \mathrm{~b}^{-/-}$and $-S h p 2^{-/-}(\mathrm{KO})$ mice compared with their respective $\mathrm{Ptp}_{1} \mathrm{~b}^{+/+}$and Shp2 $2^{+/+}$(WT) controls on a chow diet; scale bar: $200 \mu \mathrm{m}$. (B) Quantification of $\alpha \mathrm{MSH}$ staining in PVN of 5- to 6-week-old female POMC-Ptp $1 b^{-/-}$and $-S h p 2^{-/-}$mice on a chow diet ( $n=3-7$ mice per genotype, 3-4 PVN-containing sections per animal; data are expressed as percentage relative to WT controls, mean \pm SEM. (C) $\alpha \mathrm{MSH}$ peptide content in whole hypothalamus of 18-week-old male POMC-Ptp $1 b^{-/-}$and -Shp2-/- mice on HFD compared with WT controls. Data are expressed as pmol $\alpha \mathrm{MSH}$ per $\mu \mathrm{g}$ protein, mean $\pm \mathrm{SEM}$; ${ }^{* *} P<0.001$, WT versus KO by 2 -tailed Student's $t$ test.

(29). Central leptin administration (directly into the mediobasal hypothalamus of rats) can suppress lipogenesis in white adipose tissue via a PI3K-dependent mechanism (88). Expression of functional leptin receptors in leptin receptor-deficient mice resulted in dramatically improved insulin and glucose levels $(34,89)$. Similarly, expression of leptin receptors in the ARC of obese leptin receptordeficient Koletsky rats resulted in markedly improved peripheral insulin sensitivity (90). Genetic manipulations in POMC neurons implicate these specific cells as important regulators of glucose tolerance. For example, deletion of the LRb in POMC neurons (POMC-Cre:Leprflox/flox mice) results in elevated fasting glucose levels and impaired glucose tolerance when mice are maintained on a chow diet, as well as impaired insulin sensitivity compared with control mice maintained on HFD (33). In contrast, leptin-hypersensitive POMC-Socs $3^{-/}$mice display improved glucose homeostasis (35). Collectively, these studies demonstrate that central leptin and/or insulin sensitivity may have direct effects on peripheral fat metabolism and glucose homeostasis.

Consistent with the known expression pattern of POMC cells, we detected recombination of the Ptpn1 and Ptpn11 floxed alleles in pituitary, hypothalamus, and the hindbrain, making it difficult to attribute the observed phenotypes to one specific population of POMC-expressing neurons. However, serum corticosterone levels were normal in both POMC-Ptp $1 b^{-/-}$and POMC-Shp $2^{-/-}$mice, suggesting that pituitary-mediated hypothalamic-pituitary-adrenal (HPA) function is intact. Furthermore, mice with anterior pituitary-specific deletion of PTP1B (Cga-Ptp $\left.1 b^{-/-}\right)$show similar body weights and glucose levels on HFD compared with $P t p 1 b^{+/+}$ controls (Supplemental Figure 4), which argues against a primary role for PTP1B in pituitary POMC cells in mediating the observed phenotypes. Although the most extensive and well-characterized population of POMC neurons is localized to the ARC, leptinresponsive POMC neurons are also present in the NTS (91-93), and we therefore cannot rule out a possible contribution of this population to the observed phenotypes.

POMC-Ptp $1 b^{-/-}$mice were protected against HFD-induced hepatic steatosis, whereas hepatic TG content was elevated in HFD-fed POMC-Shp $2^{-/-}$mice, consistent with previous studies implicating the melanocortin pathway in regulation of hepatic lipogenesis (54, 94). Expression of $S c d 1$ and Pparg2 mRNA was reduced in livers of POMC-Ptp $1 b^{-/-}$mice and increased in steatotic livers of POMCShp $2^{-1-}$ mice. SCD-1 catalyzes the synthesis of monounsaturated fatty acids from saturated fatty acids and is therefore a major regulator of lipid synthesis (95). SCD- 1 deficiency promotes $\beta$-oxidation and decreases lipogenesis in liver and muscle; thus, mice deficient in SCD-1 have increased energy expenditure, reduced adiposity, 

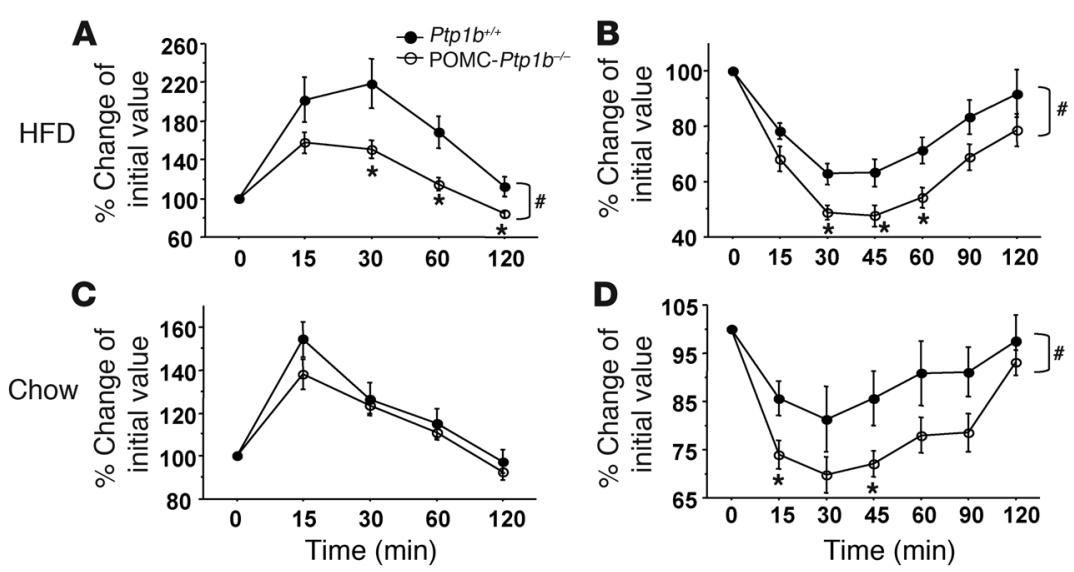

E

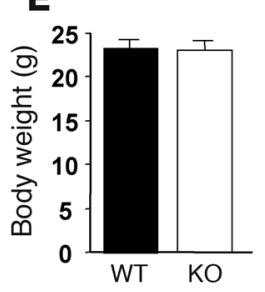

$\mathbf{F}$
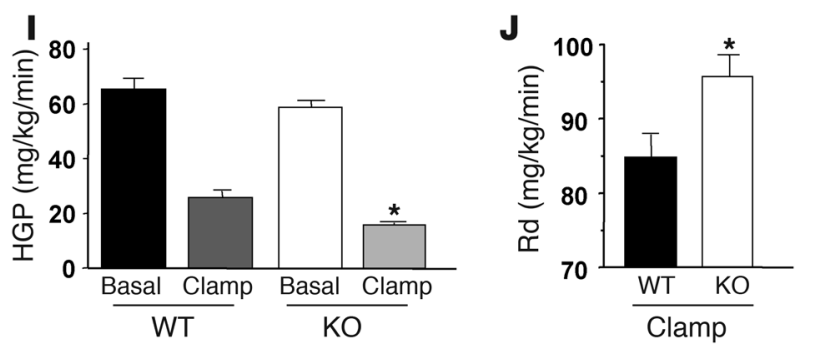

\section{Figure 9}

Insulin sensitivity and glucose homeostasis are improved in POMC-Ptp $1 b^{-/-}$mice. (A) GTT for POMC-Ptp $1 b^{-/-}$mice and Ptp $1 b^{+/+}$ control mice on HFD (8 weeks old). (B) ITT for POMC-Ptp $1 b^{-/-}$mice and Ptp $1 b^{+/+}$control mice on HFD (16 weeks old). (C) GTT for POMC-Ptp $1 b^{-/-}$mice and Ptp $1 b^{+/+}$control mice on chow diet (16 weeks old). (D) ITT for POMC-Ptp $1 b^{-/-}$mice and Ptp $1 b^{+/+}$controls on a chow diet (17 weeks old). Male mice ( $n=8 /$ genotype) were used for GTT and ITT experiments. Hyperinsulinemic-euglycemic clamp analysis of POMC-Ptp $1 b^{-/-}$mice on a chow diet reveals improved insulin sensitivity. Body weights (E), epididymal fat pad weights $(\mathbf{F})$, and basal blood glucose $(\mathbf{G})$ of male POMC-Ptp $1 b^{-/-}$mice (KO) and Ptp $1 b^{+/+}$ (WT) control mice on a chow diet were similar prior to clamp. (H) POMC-Ptp $1 b^{-/-}$mice have increased insulin sensitivity as shown by a greater GIR compared with Ptp $1 b^{+/+}$ controls. (I) POMC-Ptp $1 b^{-/-}$mice have a greater insulin-induced suppression of HGP during the clamp compared with controls (WT clamp vs. KO clamp). (J) POMC-Ptp $1 b^{-/-}$ mice have increased $\mathrm{Rd}$ compared with Ptp $1 b^{+/+}$controls. Male mice were 8 weeks of age on a chow diet ( $n=8 /$ group). All values are mean \pm SEM. ${ }^{*} P<0.05,{ }^{* *} P<0.01$ Ptp $1 b^{+/+}$versus POMC-Ptp $1 b^{-/-}$by 2 -tailed Student's $t$ test; ${ }^{P} P<0.05, P$ tp $1 b^{+/+}$versus POMC-Ptp $1 b^{-/-}$by AUC. and improved insulin sensitivity (96-98). PPAR $\gamma 2$ promotes adipogenesis; selective deletion of PPAR $\gamma 2$ in mice results in reduced adipose tissue mass and decreased adipogenesis (99). Although PPAR $\gamma 2$ is expressed mainly in adipose tissue, Pparg2 gene expression has recently been shown to be markedly upregulated in livers of human patients with nonalcoholic fatty liver (100).

The reduction in liver TG and $S c d 1$ gene expression in POMC$P t p 1 b^{-/-}$mice is consistent with enhanced leptin signaling in POMC neurons. Leptin has previously been shown to have antisteatotic effects on the liver via CNS-mediated suppression of Scd1 gene expression $(41,96)$. Mice lacking Socs3 expression in POMC neurons also display enhanced leptin sensitivity, reduced fatty liver, and decreased hepatic SCD-1 expression (35). In contrast, elevated liver TG and increased hepatic lipogenic gene expression in POMC-Shp2 $2^{-/-}$mice are consistent with leptin resistance. Interestingly, neuronal $\operatorname{Shp} 2^{-/-}$mice showed similar increases in hepatic lipid content and hepatic lipogenic gene expression as early as postnatal day 28 , suggesting that these changes in gene expression precede the development of obesity (27).

Taken together, our results identify PTP1B and SHP2 as essential contributors to POMC neuron regulation of energy balance. PTP1B deficiency in POMC neurons results in protection from weight gain on HFD and in improved insulin sensitivity independent of body weight and adiposity on a low-fat chow diet.
We also present evidence that SHP2 deficiency in POMC neurons leads to obesity on either a chow diet or HFD, likely due to impaired functioning of the melanocortin system at a young age. In addition, these studies define what we believe to be a novel role for these PTPs in CNS control of diet-induced hepatic steatosis, which may have important therapeutic implications for diet-induced fatty liver disease.

\section{Methods}

Animal care. All animal care protocols and procedures were approved by the University of Pennsylvania Institutional Care and Use Committee. We maintained mice on a 12-hour light/12-hour dark cycle in a temperaturecontrolled barrier facility, with free access to water and food (standard chow autoclavable Lab Diet 5010 or custom HFD Teklad TD93075) (101). Age-matched littermates were used for all experiments.

Mice with POMC-specific deletion of PTP1B or SHP2. Ptpn $1^{\text {loxP/loxP }}$ mice were generated previously and genotyped by PCR as described (19). Ptpn $11^{\text {loxP / loxP }}$ mice were a gift from B. Neel (Ontario Cancer Institute, Toronto, Canada) (36). Genotyping primer sequences for the Ptpn1 allele were: PTP1B forward 5'-TGCTCACTCACCCTGCTACAA, reverse 5'-GAAATGGCTCACTCCTACTGG; genotyping primers for the Ptpn11 allele were: SHP2 forward 5'-TAGCTGCTTTAACCCTCTGTGT, reverse 5'-CATCAGAGCAGGCCATATTCC; primers for POMC-Cre were: POMC forward 5'-TGGCTCAATGTCCTTCCTGG, WT reverse 5'-CACATAAGCTGCATCGTTAAG, 
Cre reverse 5'-GAGATATCTTTAACCCTGATC. DNA was extracted from a drop of blood from each experimental animal to check for the occurrence of spurious germline deletion using the following primers: $P t p n 1^{\Delta / \Delta}$ forward 5'-GTGGTGCCTGCAAGAGAACTGAC, reverse 5'-GAAATGGCTCACTCCTACTGG; Ptpn $11^{\Delta / \Delta}$ forward 5'-TAGCTGCTTTAACCCTCTGTGT, reverse 5'-AATTGCGGCTTCTTGTCCT; IL-2 primers were used as an internal control (Jax primers forward 5 '-CTAGGCCACAGAATTGAAAGATCT-3'; reverse 5'-GTAGGTGGAAATTCTAGCATCATCC-3'); Z/EG reporter mice (The Jackson Laboratory, stock 003920; ref. 102) were genotyped using the following GFP primers: forward 5'-TCATGGCCGACAAGCAGAAGAACG-3', reverse 5'-CGGCGGCGGTCACGAACT-3'. All experiments used $P \operatorname{tpn} 1^{\text {loxP } / l o x P}$ and $P \operatorname{tpn} 11^{\text {loxP } P \text { loxP }}$ mice that were originally on a mixed $129 \mathrm{~Sv} / \mathrm{J} \times \mathrm{C} 57 \mathrm{BL} / 6$ background but were backcrossed at least 3 generations onto C57BL/ 6 prior to mating with POMC-Cre mice (gift from B. Lowell, Beth Israel Deaconess Medical Center, Boston, Massachusetts, and J. Elmquist, University of Texas Southwestern Medical Center, Dallas). POMC-Cre mice (31) were backcrossed more than 6 generations onto a C57BL/ 6 background. Cga-Cre transgenic mice (C57BL/6J; The Jackson Laboratory, stock 004426) express Cre recombinase under the control of the mouse glycoprotein hormone $\alpha$-subunit promoter.

Isolating DNA from tissues for detection of recombination of the floxed alleles. Tissues were digested at $55^{\circ} \mathrm{C}$ overnight in proteinase $\mathrm{K}$ digestion buffer (100 mM Tris- $\mathrm{HCl} \mathrm{pH}$ 8.5, 5 mM EDTA, 0.2\% SDS, $200 \mathrm{mM} \mathrm{NaCl}$, $300 \mu \mathrm{g} / \mathrm{ml}$ proteinase $\mathrm{K})$. Saturated $\mathrm{NaCl}(\sim 6 \mathrm{M})$ was added to the digestion, and samples were vortexed vigorously for 1 minute. Samples were centrifuged for 20 minutes at $13,700 \mathrm{~g}$, and supernatants were transferred to a fresh tube. DNA was precipitated by adding $1 \mathrm{ml} 100 \%$ ethanol, and pellets were washed once with $70 \%$ ethanol and were resuspended in $100 \mu \mathrm{l}$ of sterile PCR water for analysis. PCR for the recombined alleles was performed as described above.

Immunobistochemistry. To prevent the secretion of $\alpha \mathrm{MSH}$ from the POMC cell body, we blocked axonal transport by injection of colchicine (Sigma-Aldrich; $40 \mu \mathrm{g}$ in $2 \mu \mathrm{l}$ of $0.9 \% \mathrm{NaCl}$ ) into the right lateral ventricle of the brain. Anesthetized mice were placed into a stereotactic device and implanted with a cannula (Plastics One) $0.34 \mathrm{~mm}$ posterior to bregma, $1.0 \mathrm{~mm}$ lateral to the midline, and $2.6 \mathrm{~mm}$ below the surface of the skull. The cannula was connected via tubing to a Hamilton 5.0- $\mu 1$ syringe, and colchicine was injected over 30 seconds. Forty-eight hours after colchicine injection, the animals were deeply anesthetized with sodium pentobarbital $(50 \mathrm{mg} / \mathrm{kg}$, i.p.) and perfused via transcardial perfusion with $1 \times$ PBS followed by ice-cold $4 \%$ PFA. Brains were postfixed for 4 hours in $4 \%$ PFA and cryoprotected overnight in $20 \%$ sucrose in $1 \times \mathrm{PBS}$ at $4^{\circ} \mathrm{C}$. Eight series of 30- $\mu \mathrm{M}$ free-floating sections were cut via a sliding microtome, collected in cold ethylene glycol-based cryoprotectant, and stored at $-20^{\circ} \mathrm{C}$ until processing. Endogenous peroxidase activity was neutralized by treating tissue for 30 minutes with $0.3 \%$ hydrogen peroxide. Cells were permeabilized with PBS/0.3\% Triton X-100 plus 3\% normal rabbit serum for 1 hour. Sections were incubated with sheep polyclonal antiserum directed against the $\mathrm{C}$-terminal region of the $\alpha \mathrm{MSH}$ (Chemicon International, AB0587; 1:10,000) overnight at $4^{\circ} \mathrm{C}$, washed in PBS, incubated with biotinylated secondary antibody (Vector Laboratories; 1:200) for 1 hour at room temperature, followed by washes in PBS. Localization was performed using a conventional avidin-biotin immunoperoxidase method as previously described (Vectastain Elite ABC Kit, Vector Laboratories) (103). Sections were placed on slides, air dried, and coverslipped with Vectashield (Vector Laboratories). For GFP analysis, the same procedure was performed as described above, except $2 \%$ normal goat serum was used as the blocking agent and anti-GFP rabbit polyclonal antisera was used as the primary antibody (Invitrogen, A6455; 1:20,000). For $\alpha \mathrm{MSH}$ projections, mice were sacrificed and tissue collected, stored, and processed using procedures identical to those presented above, except that Cy3-conjugated donkey anti-sheep IgG (Jackson ImmunoResearch Laboratories Inc.; 1:100) was used as the secondary antibody (2-hour incubation at room temperature). Adrenocorticotropic hormone/pStat 3 double labeling. Mice were fasted overnight (16 hours) and injected with mouse recombinant leptin i.p. (A.F. Parlow, National Hormone and Peptide Program [NHPP], Harbor-UCLA Medical Center, Torrance, California; $3 \mu \mathrm{g} / \mathrm{g}$ ). Forty-five minutes after injection, mice were anesthetized and perfused and tissue processed as described above. For immunofluorescence analysis, sections were washed with $1 \times$ PBS prior to and between successive blocking steps with $1.0 \%$ $\mathrm{H}_{2} \mathrm{O}_{2} / 1.0 \% \mathrm{NaOH}$ in $\mathrm{H}_{2} \mathrm{O}$ (20 minutes), $0.3 \%$ glycine (10 minutes), $0.03 \%$ SDS (10 minutes), and finally $0.2 \%$ sodium azide $/ 3 \%$ normal donkey serum $/ 0.25 \%$ Triton X-100 in PBS (1 hour). Sections were then incubated with pStat 3 primary antibody (rabbit anti-pStat3; Cell Signaling Technology, 9131) diluted 1:2,000 in azide blocking solution overnight. The following day, sections were washed with $1 \times$ PBS and subsequently in sodium azide-free blocking solution containing secondary antibody (donkey anti-rabbit Dylight 549; 1:200; Jackson ImmunoResearch Laboratories) for 1 hour. Sections were washed with $1 \times$ PBS and placed in 3\% normal donkey serum $/ 0.25 \%$ Triton X-100 in PBS for 1 hour and then incubated with adrenocorticotropic hormone (ACTH) primary antibody (1:1,000 in 3\% normal serum/0.25\% Triton X-100 in PBS) overnight (rabbit anti-ACTH; A.F. Parlow, NHPP). On the third day, after washes with $1 \times$ PBS, sections were incubated in secondary antibody (donkey anti-rabbit Dylight 488; 1:200; Jackson ImmunoResearch Laboratories) in 3\% normal serum $/ 0.25 \%$ Triton X-100) for 1 hour at room temperature. After washing in $1 \times$ PBS, sections were placed on slides, air dried, and coverslipped with Vectashield (Vector Labs).

Imaging and quantification. All images for each experiment were captured using a Nikon 80i fluorescence microscope and CCD camera and viewed using NIS-Elements software. Counts were manually quantified by an individual blinded to the genotype of the animals. $\alpha \mathrm{MSH}$-positive cells were counted in 2-4 serial sections per animal within the ARC $(-1.46 \mathrm{~mm}$ to $-1.58 \mathrm{~mm}$ from bregma [based on coordinates in ref. 104]). Data are presented as the average number of stained cells per section counted. Cell diameter was measured using NIS-Elements software. Only cells within the plane of focus and containing a clearly defined outer perimeter were selected for analysis. $\alpha \mathrm{MSH}$ fibers in the PVN were quantified and expressed as percentage of wild-type control animals. Briefly, bilateral regions of interest (ROIs) containing the entire PVN were drawn; the same ROIs were used for all sections for consistency $(\times 60$ total magnification). $\alpha \mathrm{MSH}$-positive fibers were quantified as the percentage of area covered within the ROI (with signal above background). A total of 3-7 animals were analyzed per genotype, and $2-5$ sections per animal were quantified ( $-0.82 \mathrm{~mm}$ to $-1.06 \mathrm{~mm}$ from bregma; ref. 104). All staining was performed in paired WT and KO groups, and image quantification was done simultaneously to avoid variability.

Cells double-labeled for pStat 3 and ACTH were counted bilaterally in the ARC in 3 individual sections at approximately $-1.46 \mathrm{~mm}$ from bregma (104). Three sections were analyzed for each genotype $(n=3$ mice per genotype). Data are presented as the percentage of ACTH cells that were also pStat3-positive.

Immunoblotting. Mouse tissues were dissected and immediately frozen in liquid nitrogen. Whole-cell lysates were prepared in modified RIPA buffer containing fresh protease inhibitors, and PTP1B, SHP2, and ERK2 immunoblotting was performed as described previously (16). PTP1B immunoblots were normalized to SHP2 (Santa Cruz Biotechnology Inc., sc-280), and SHP2 blots were normalized to ERK2 (Santa Cruz Biotechnology Inc., sc-154) to control for loading. Blots were quantified using NIH ImageJ software (http://rsbweb.nih.gov/ij/). 
Body composition and food intake. At weaning, mice were placed on diets of either standard laboratory chow (Lab Diet 5010; calories provided by protein [28.7\%], fat [12.7\%], and carbohydrate [58.5\%]) or custom HFD (Teklad TD93075; calories provided by protein [21.2\%], fat [54.8\%], and carbohydrate [24\%]). Body weights and food intake were assessed weekly for at least 16 weeks. Feed efficiency was calculated as grams of body weight gained per grams of food consumed over a 3-day period (105). Epididymal fat pads were dissected and weighed at the indicated age. Total lean mass, fat mass, and nose-rump length of mice on HFD was determined by DEXA (PIXImus DEXA; GE).

Energy expenditure measurements. Mice were acclimated to the test cage for 24 hours, and energy expenditure was measured at 15 -minute intervals for 24 hours on the second day (Oxymax Equal Flow System; Columbus Instruments). $\mathrm{V}_{\mathrm{O} 2}$ and carbon dioxide production $\left(\mathrm{V}_{\mathrm{CO} 2}\right)$ were measured using electrochemical and spectrophotometric sensors. RQ was calculated as the ratio of $\mathrm{V}_{\mathrm{CO} 2}$ to $\mathrm{V}_{\mathrm{O} 2}$. Locomotor activity was measured simultaneously by infrared beam interruption (Optovarimax System; Columbus Instruments) and is reported as average counts per hour. Rectal temperature was measured with a thermistor (MicroTherma 2T; ThermoWorks).

Leptin sensitivity. For in vivo leptin sensitivity measurements, recombinant mouse leptin (A.F. Parlow, NHPP) or $0.9 \%$ saline was administered i.p. to male mice on a chow diet ( $>-10$ weeks of age). Mice were fasted overnight prior to injections. Leptin was given i.p. every 12 hours (morning and evening; dose for PTP1B experiments, $0.5 \mu \mathrm{g} / \mathrm{g} /$ injection, dose for SHP2 experiments, $2.0 \mu \mathrm{g} / \mathrm{g} /$ injection) for the indicated period of time (36 hours). Body weight and food intake were monitored daily for 5 days. Body weight and baseline food intake measurements for the 2 days prior to the start of the experiment were averaged and used to calculate percent change.

Glucose homeostasis. Blood glucose was assayed in tail blood using a glucometer (Ascensia ELITE XL, Bayer). Measurements were taken at the onset of the light cycle (between 08:00 and 10:00 a.m.). ITTs and GTTs were performed as described previously (101). The insulin dose used for i.p. injections was $1.2 \mathrm{mU} / \mathrm{g} \mathrm{BW}$ in mice on HFD and $1.0 \mathrm{mU} / \mathrm{g} \mathrm{BW}$ in mice on a chow diet. Glucose dose used for i.p. injections was $2 \mathrm{mg} / \mathrm{g} B W$.

Hyperinsulinemic-euglycemic clamp. Insulin clamp experiments were performed in male mice on a chow diet. The mice were catheterized via the right internal jugular vein under sodium pentobarbital anesthesia and allowed 5 days to recover $(106,107)$. Food was removed, and 5 hours later $\left[3-{ }^{3} \mathrm{H}\right]$ glucose was infused intravenously to assess basal glucose kinetics, followed by hyperinsulinemic-euglycemic clamp for 120 minutes. A priming intravenous injection of human insulin ( $40 \mathrm{mU} / \mathrm{kg}$; Humulin, Eli Lilly) was administered, followed by continuous infusion at $10 \mathrm{mU} / \mathrm{kg} / \mathrm{min}$. Tail blood samples $(10 \mu \mathrm{l})$ were collected at 20 -minute intervals for measurement of glucose, and $30 \%$ glucose was infused to maintain blood glucose between 120 and $140 \mathrm{mg} / \mathrm{dl}$. Insulin-stimulated whole-body glucose flux was assessed by injecting a 10-mCi high-performance liquid chromatography-purified $\left[3-{ }^{3} \mathrm{H}\right]$ glucose bolus and infusing continuously at $0.1 \mathrm{mCi} / \mathrm{min}$. Once steady state was attained for 60 minutes, $20-\mu \mathrm{l}$ blood samples were collected at 10-minute intervals for measurement of $\left[{ }^{3} \mathrm{H}\right]$ glucose and ${ }^{3} \mathrm{H}_{2} \mathrm{O}$. The GIR, endogenous glucose production (mostly HGP), and Rd were determined as previously described $(106,107)$. For POMC-Shp $2^{-/-}$and control mice, body composition was measured in conscious mice by NMR just prior to the clamp to allow for selection of fat-matched animals (Echo Medical Systems).

Hepatic TG content. Frozen pieces of liver $(\sim 100 \mathrm{mg})$ were homogenized in glass tubes, and tissue lipids were extracted with $2 \mathrm{ml}$ of 2:1 chloroform/ methanol. Samples were spun at $500 \mathrm{~g}$ for 5 minutes at room temperature; $1 \mathrm{ml}$ of the supernatant layer was transferred to a new tube, and samples were dried under air for 8-10 hours, then solubilized in $1 \mathrm{ml}$ of isopropanol. Total TG content was measured by enzymatic assay (Sigma-Aldrich, TR0100), and TG content was normalized to starting tissue weight.
RNA extraction and real-time PCR. Mice were sacrificed at the onset of the light cycle (08:00-10:00 a.m.) after either 24 hours of food withdrawal (fasted) or free access to food (fed) as indicated. Tissues (whole hypothalamus or liver) were rapidly dissected and flash frozen in liquid nitrogen. Total RNA was extracted from tissues using TRIzol (Invitrogen) and the RNeasy kit (QIAGEN). cDNA was synthesized from $1 \mu \mathrm{g}$ total RNA using the High-Capacity cDNA Reverse Transcription Kit (Applied Biosystems). The relative mRNA levels of AgRP, NPY, POMC, SCD-1, and PPAR $\gamma 2$ were assessed and quantified by quantitative real-time PCR (qRT-PCR). HPRT-1 and $18 \mathrm{~S}$ (SABiosciences) were used as internal controls. The qRT-PCR reactions were carried out using RT2 SYBR Green qPCR Master Mix (SABiosciences), and samples were run using the Eppendorf Mastercycler ep realplex. The sequences of primers for AgRP, NPY, and POMC were the same as previously described (19); PPAR $\gamma 2$ primers were from SABiosciences (PPM05108B-200), and SCD-1 expression was analyzed using a TaqMan gene expression kit from Applied Biosystems (Mm00772290_m1). Relative mRNA expression was calculated using the comparative $\mathrm{Ct}$ method as described previously (19).

Serum analysis. Blood was collected by tail bleeding mice at the beginning of the light cycle (between 08:00 and 10:00 a.m.) when animals were in the fed state. Serum was separated by centrifugation at $6,000 \mathrm{~g}$. Serum insulin and leptin (CrystalChem) and serum adiponectin (Linco Research) were measured by ELISAs. Serum corticosterone levels were measured by ${ }^{125}$ I radioimmunoassay (MP Biomedicals). FFAs (Wako) and serum TGs (Sigma-Aldrich) were measured by enzymatic assay.

$\alpha M S H$ content in hypothalamus. Hypothalami were immersed in $2 \mathrm{M}$ acetic acid and boiled for 10 minutes. Samples were sonicated briefly and centrifuged at $21,000 \mathrm{~g}$ at $4{ }^{\circ} \mathrm{C}$ for 30 minutes. Supernatants were collected and protein concentration measured by BCA assay. Samples were acidified and peptides purified over C-18 Sep-columns (200 mg) according to the manufacturer's protocol (Phoenix Pharmaceuticals Inc.) and as described previously $(108,109)$. The elution fraction was dried overnight in a Speed-Vac and reconstituted in $120 \mu \mathrm{l}$ assay buffer, and $\alpha \mathrm{MSH}$ levels were measured by enzyme immunoassay (Phoenix Pharmaceuticals EK-043-01). Data are expressed as $\mathrm{pmol} / \mathrm{\mu g}$ protein.

Statistics. Results are expressed as mean \pm SEM. Comparisons between groups were made by unpaired 2-tailed Student's $t$ test or ANOVA followed by Fisher's protected least significant difference (PLSD) test, as appropriate. A $P$ value less than 0.05 was considered to be statistically significant.

\section{Acknowledgments}

This research was supported in part by NIH grant R01DK082417 (to K.K. Bence), the University of Pennsylvania Diabetes Endocrinology Research Center and the Mouse Phenotyping, Physiology and Metabolism Core (NIDDK grant 5P30DK019525), the University of Pennsylvania Research Foundation, and the Thomas B. and Jeannette E. Laws McCabe Fund. Initial portions of this study were performed in Benjamin G. Neel's laboratory (NIH grant R01 CA 49152). We thank Caitlin Kauffman and Ravindra Dhir for excellent technical assistance, Teresa Reyes for technical advice on immunohistochemistry, Matthew Hayes and Harvey Grill for assistance with their microscope, and Rex Ahima for helpful discussions.

Received for publication April 21, 2009, and accepted in revised form December 16, 2009.

Address correspondence to: Kendra K. Bence, University of Pennsylvania, School of Veterinary Medicine, 3800 Spruce Street, Vet 223E, Philadelphia, PA 19104-6046, USA. Phone: 215.746.2998; Fax: 215.573.5186; E-mail: kbence@vet.upenn.edu. 
1. Ahima RS. Obesity epidemic in need of answers. Gastroenterology. 2006;131(4):991.

2. Obici S. Minireview: molecular targets for obesity therapy in the brain. Endocrinology. 2009; 150(6):2512-2517.

3. Konturek PC, et al. Neuro-hormonal control of food intake: basic mechanisms and clinical implications. J Physiol Pharmacol. 2005;56(suppl 6):5-25.

4. Schwartz MW, Woods SC, Porte D Jr, Seeley RJ. Baskin, DG. Central nervous system control of food intake. Nature. 2000;404(6778):661-671.

5. Baskin DG, et al. Insulin and leptin: dual adiposity signals to the brain for the regulation of food intake and body weight. Brain Res. 1999;848(1-2):114-123.

6. Bouret SG, Draper SJ, Simerly RB. Formation of projection pathways from the arcuate nucleus of the hypothalamus to hypothalamic regions implicated in the neural control of feeding behavior in mice. J Neurosci. 2004;24(11):2797-2805.

7. Elias CF, et al. Leptin differentially regulates NPY and POMC neurons projecting to the lateral hypothalamic area. Neuron. 1999;23(4):775-786.

8. Hahn TM, Breininger JF, Baskin DG, Schwartz MW. Coexpression of Agrp and NPY in fasting-activated hypothalamic neurons. Nat Neurosci. 1998; 1(4):271-272.

9. Coll AP, Farooqi IS, Challis BG, Yeo GS, O’Rahilly S. Proopiomelanocortin and energy balance: insights from human and murine genetics. J Clin Endocrinol Metab. 2004;89(6):2557-2562.

10. Cowley MA, et al. Leptin activates anorexigenic POMC neurons through a neural network in the arcuate nucleus. Nature. 2001;411(6836):480-484.

11. Morton GJ, Schwartz MW. The NPY/AgRP neuron and energy homeostasis. Int J Obes Relat Metab Disord. 2001;25(Suppl 5):S56-S62.

12. Friedman JM, Halaas JL. Leptin and the regulation of body weight in mammals. Nature. 1998 395(6704):763-770.

13. Mantzoros CS, Flier JS. Editorial: leptin as a therapeutic agent - trials and tribulations. J Clin Endocrinol Metab. 2000;85(11):4000-4002.

14. Scarpace PJ, Zhang Y. Elevated leptin: consequence or cause of obesity? Front Biosci. 2007;12:3531-3544.

15. Munzberg H, Myers MG Jr. Molecular and anatomical determinants of central leptin resistance. Nat Neurosci. 2005;8(5):566-570.

16. Zabolotny JM, et al. PTP1B regulates leptin signal transduction in vivo. Dev Cell. 2002;2(4):489-495.

17. Cheng A, et al. Attenuation of leptin action and regulation of obesity by protein tyrosine phosphatase 1B. Dev Cell. 2002;2(4):497-503.

18. Myers MP, et al. TYK2 and JAK2 are substrates of protein-tyrosine phosphatase 1B. J Biol Chem. 2001; 276(51):47771-47774.

19. Bence KK, et al. Neuronal PTP1B regulates body weight, adiposity and leptin action. Nat Med. 2006 12(8):917-924.

20. Delibegovic M, et al. Improved glucose homeostasis in mice with muscle-specific deletion of protein-tyrosine phosphatase 1B. Mol Cell Biol. 2007; 27(21):7727-7734.

21. Delibegovic M, et al. Liver-specific deletion of protein-tyrosine phosphatase 1B (PTP1B) improves metabolic syndrome and attenuates diet-induced endoplasmic reticulum stress. Diabetes. 2009; 58(3):590-599.

22. Zhang S, Zhang ZY. PTP1B as a drug target: recent developments in PTP1B inhibitor discovery. Drug Discov Today. 2007;12(9-10):373-381.

23. Neel BG, Gu H, Pao L. The 'Shp'ing news: SH2 domain-containing tyrosine phosphatases in cell signaling. Trends Biochem Sci. 2003;28(6):284-293.

24. Feng GS. Shp2 as a therapeutic target for leptin resistance and obesity. Expert Opin Ther Targets. 2006;10(1):135-142.

25. Bjorbaek C, et al. Divergent roles of SHP-2 in ERK activation by leptin receptors. J Biol Chem. 2001;
276(7):4747-4755.

26. Banks AS, Davis SM, Bates SH, Myers MG Jr. Activation of downstream signals by the long form of the leptin receptor. J Biol Chem. 2000; 275(19):14563-14572.

27. Zhang EE, Chapeau E, Hagihara K, Feng GS. Neuronal Shp2 tyrosine phosphatase controls energy balance and metabolism. Proc Natl Acad Sci US A. 2004;101(45):16064-16069.

28. Krajewska M, et al. Development of diabesity in mice with neuronal deletion of Shp2 tyrosine phosphatase. Am J Pathol. 2008;172(5):1312-1324.

29. Parton LE, et al. Glucose sensing by POMC neurons regulates glucose homeostasis and is impaired in obesity. Nature. 2007;449(7159):228-232.

30 . Farooqi S. Insights from the genetics of severe childhood obesity. Horm Res. 2007;68(Suppl 5):5-7.

31. Balthasar $\mathrm{N}$, et al. Leptin receptor signaling in POMC neurons is required for normal body weight homeostasis. Neuron. 2004;42(6):983-991.

32. van de Wall E, et al. Collective and individual functions of leptin receptor modulated neurons controlling metabolism and ingestion. Endocrinology. 2008;149(4):1773-1785.

33. Shi H, Strader AD, Sorrell JE, Chambers JB, Woods SC, Seeley RJ. Sexually different actions of leptin in proopiomelanocortin neurons to regulate glucose homeostasis. Am J Physiol Endocrinol Metab. 2008; 294(3):E630-E639.

34. Huo L, et al. Leptin-dependent control of glucose balance and locomotor activity by POMC neurons. Cell Metab. 2009;9(6):537-547.

35. Kievit P, et al. Enhanced leptin sensitivity and improved glucose homeostasis in mice lacking suppressor of cytokine signaling- 3 in POMC-expressing cells. Cell Metab. 2006;4(2):123-132.

36. Fornaro M, et al. SHP-2 activates signaling of the nuclear factor of activated $\mathrm{T}$ cells to promote skeletal muscle growth. J Cell Biol. 2006;175(1):87-97.

37. Meier U, Gressner AM. Endocrine regulation of energy metabolism: review of pathobiochemical and clinical chemical aspects of leptin, ghrelin, adiponectin, and resistin. Clin Chem. 2004;50(9):1511-1525.

38. Haluzik M, Parizkova J, Haluzik MM. Adiponectin and its role in the obesity-induced insulin resistance and related complications. Physiol Res. 2004;53(2):123-129.

39. Combs TP, Berg AH, Obici S, Scherer PE, Rossetti L. Endogenous glucose production is inhibited by the adipose-derived protein Acrp30. J Clin Invest. 2001;108(12):1875-1881.

40. Buettner R, Scholmerich J, Bollheimer LC. High-fat diets: modeling the metabolic disorders of human obesity in rodents. Obesity (Silver Spring). 2007; 15(4):798-808.

41. Asilmaz E, et al. Site and mechanism of leptin action in a rodent form of congenital lipodystrophy. J Clin Invest. 2004;113(3):414-424.

42. Elmquist JK, Bjorbaek C, Ahima RS, Flier JS, Saper CB. Distributions of leptin receptor mRNA isoforms in the rat brain. J Comp Neurol. 1998; 395(4):535-547.

43. Funahashi H, Yada T, Suzuki R, Shioda S. Distribution, function, and properties of leptin receptors in the brain. Int Rev Cytol. 2003;224:1-27.

44. Myers MG Jr, Munzberg H, Leinninger GM, Leshan RL. The geometry of leptin action in the brain: more complicated than a simple ARC. Cell Metab. 2009;9(2):117-123.

45. Sweeney G. Leptin signalling. Cell Signal. 2002; 14(8):655-663.

46. Bjorbaek C, Kahn BB. Leptin signaling in the central nervous system and the periphery. Recent Prog Horm Res. 2004;59:305-331.

47. Ahima RS, Osei SY. Leptin signaling. Physiol Behav. 2004;81(2):223-241.

48. Leshan RL, Bjornholm M, Munzberg H, Myers MG Jr. Leptin receptor signaling and action in the central nervous system. Obesity (Silver Spring). 2006; 14(Suppl 5):208S-212S.

49. Myers MG, Cowley MA, Munzberg H. Mechanisms of leptin action and leptin resistance. Annu Rev Physiol. 2008;70:537-556.

50. Zabolotny JM, Kim YB, Welsh LA, Kershaw EE, Neel BG, Kahn BB. Protein-tyrosine phosphatase $1 \mathrm{~B}$ expression is induced by inflammation in vivo. J Biol Chem. 2008;283(21):14230-14241.

51. White CL, Whittington A, Barnes MJ, Wang Z, Bray GA, Morrison CD. HF diets increase hypothalamic PTP1B and induce leptin resistance through both leptin-dependent and -independent mechanisms. Am J Physiol Endocrinol Metab. 2009;296(2):E291-E299.

52. Elchebly M, Cheng A, Tremblay ML. Modulation of insulin signaling by protein tyrosine phosphatases. J Mol Med. 2000;78(9):473-482.

53. Bourdeau A, Dube N, Tremblay ML. Cytoplasmic protein tyrosine phosphatases, regulation and function: the roles of PTP1B and TC-PTP. Curr Opin Cell Biol. 2005;17(2):203-209.

54. Obici S, Feng Z, Tan J, Liu L, Karkanias G, Rossetti L. Central melanocortin receptors regulate insulin action. J Clin Invest. 2001;108(7):1079-1085.

55. Obici S, Zhang BB, Karkanias G, Rossetti L. Hypothalamic insulin signaling is required for inhibition of glucose production. Nat Med. 2002;8(12):1376-1382.

56 . Koch L, et al. Central insulin action regulates peripheral glucose and fat metabolism in mice.J Clin Invest. 2008;118(6):2132-2147.

57 . Bruning JC, et al. Role of brain insulin receptor in control of body weight and reproduction. Science. 2000;289(5487):2122-2125.

58. Plum L, Schubert M, Bruning JC. The role of insulin receptor signaling in the brain. Trends Endocrinol Metab. 2005;16(2):59-65.

59. Plum L, Belgardt BF, Bruning JC. Central insulin action in energy and glucose homeostasis. J Clin Invest. 2006;116(7):1761-1766.

60 . Benoit SC, et al. The catabolic action of insulin in the brain is mediated by melanocortins. J Neurosci. 2002;22(20):9048-9052.

61. Niswender KD, et al. Insulin activation of phosphatidylinositol 3-kinase in the hypothalamic arcuate nucleus: a key mediator of insulin-induced anorexia. Diabetes. 2003;52(2):227-231.

62. Xu AW, Kaelin CB, Takeda K, Akira S, Schwartz MW, Barsh GS. PI3K integrates the action of insulin and leptin on hypothalamic neurons. J Clin Invest. 2005;115(4):951-958.

63. Plum L, et al. Enhanced PIP3 signaling in POMC neurons causes KATP channel activation and leads to diet-sensitive obesity. J Clin Invest. 2006; 116(7):1886-1901.

64. Konner AC, et al. Insulin action in AgRP-expressing neurons is required for suppression of hepatic glucose production. Cell Metab. 2007;5(6):438-449.

65. Choudhury AI, et al. The role of insulin receptor substrate 2 in hypothalamic and beta cell function. J Clin Invest. 2005;115(4):940-950.

66. Heinrich PC, Behrmann I, Muller-Newen G, Schaper F, Graeve L. Interleukin-6-type cytokine signalling through the gp130/Jak/STAT pathway. Biochem J. 1998;334(pt 2):297-314

67. Janoschek R, et al. gp130 signaling in proopiomelanocortin neurons mediates the acute anorectic response to centrally applied ciliary neurotrophic factor. Proc Natl Acad Sci U S A. 2006;103(28):10707-10712.

68. Bouret SG, Draper SJ, Simerly RB. Trophic action of leptin on hypothalamic neurons that regulate feeding. Science. 2004;304(5667):108-110.

69. Horvath TL, Bruning JC. Developmental programming of the hypothalamus: a matter of fat. Nat Med. 2006;12(1):52-53.

70. Bouret SG, Simerly RB. Development of leptin-sensitive circuits. J Neuroendocrinol. 2007;19(8):575-582.

71. Bouret SG, Gorski JN, Patterson CM, Chen S, Levin BE, Simerly RB. Hypothalamic neural projections 
are permanently disrupted in diet-induced obese rats. Cell Metab. 2008;7(2):179-185.

72. Bjornholm M, et al. Mice lacking inhibitory leptin receptor signals are lean with normal endocrine function. J Clin Invest. 2007;117(5):1354-1360.

73. Neel BG, Tonks NK. Protein tyrosine phosphatases in signal transduction. Curr Opin Cell Biol. 1997; 9(2):193-204.

74. Feng GS. Shp-2 tyrosine phosphatase: signaling one cell or many. Exp Cell Res. 1999;253(1):47-54.

75. Walter AO, Peng ZY, Cartwright CA. The Shp-2 tyrosine phosphatase activates the Src tyrosine kinase by a non-enzymatic mechanism. Oncogene. 1999; 18(11):1911-1920.

76. Maness PF, Aubry M, Shores CG, Frame L, Pfenninger KH. c-src gene product in developing rat brain is enriched in nerve growth cone membranes. Proc Natl Acad Sci U S A. 1988;85(14):5001-5005.

77. Bixby JL, Jhabvala P. Tyrosine phosphorylation in early embryonic growth cones. J Neurosci. 1993; 13(8):3421-3432.

78. Morse WR, Whitesides JG 3rd, LaMantia AS, Maness PF. p59fyn and pp60c-src modulate axonal guidance in the developing mouse olfactory pathway. J Neurobiol. 1998;36(1):53-63.

79. Besset V, Scott RP, Ibanez CF. Signaling complexes and protein-protein interactions involved in the activation of the Ras and phosphatidylinositol 3-kinase pathways by the c-Ret receptor tyrosine kinase. J Biol Chem. 2000;275(50):39159-39166.

80. D'Alessio A, et al. The tyrosine phosphatase Shp-2 mediates intracellular signaling initiated by Ret mutants. Endocrinology. 2003;144(10):4298-4305.

81. Enomoto $\mathrm{H}$, et al. RET signaling is essential for migration, axonal growth and axon guidance of developing sympathetic neurons. Development. 2001; 128(20):3963-3974.

82. Chen B, Hammonds-Odie L, Perron J, Masters BA, Bixby JL. SHP-2 mediates target-regulated axonal termination and NGF-dependent neurite growth in sympathetic neurons. Dev Biol. 2002;252(2):170-187.

83. Williams KW, Scott MM, Elmquist JK. From observation to experimentation: leptin action in the mediobasal hypothalamus. Am J Clin Nutr. 2009; 89(3):985S-990S

84. Grill HJ. Distributed neural control of energy balance: contributions from hindbrain and hypothalamus. Obesity (Silver Spring). 2006;14(Suppl 5):216S-221S

85. Prodi E, Obici S. Minireview: the brain as a molecular target for diabetic therapy. Endocrinology. 2006; 147(6):2664-2669

86. Koshiyama H, Hamamoto Y, Honjo S, Wada Y, Lkeda H. Hypothalamic pathogenesis of type 2 diabetes. Med Hypotheses. 2006;67(2):307-310.

87. Pocai A, Obici S, Schwartz GJ, Rossetti L. A brainliver circuit regulates glucose homeostasis. Cell Metab. 2005;1(1):53-61.

88. Buettner C, et al. Leptin controls adipose tissue lipogenesis via central, STAT3-independent mechanisms. Nat Med. 2008;14(6):667-675.

89. Coppari R, et al. The hypothalamic arcuate nucleus: a key site for mediating leptin's effects on glucose homeostasis and locomotor activity. Cell Metab.2005 1(1):63-72.

90. Morton GJ, et al. Leptin regulates insulin sensitivity via phosphatidylinositol-3-OH kinase signaling in mediobasal hypothalamic neurons. Cell Metab. 2005; 2(6):411-420.

91. Ellacott KL, Halatchev IG, Cone RD. Characterization of leptin-responsive neurons in the caudal brainstem. Endocrinology. 2006;147(7):3190-3195.

92. Bronstein DM, Schafer MK, Watson SJ, Akil H. Evidence that beta-endorphin is synthesized in cells in the nucleus tractus solitarius: detection of POMC mRNA. Brain Res. 1992;587(2):269-275.

93. Palkovits M, Eskay RL. Distribution and possible origin of beta-endorphin and ACTH in discrete brainstem nuclei of rats. Neuropeptides. 1987 9(2):123-137.

94. Mizuno TM, Kelley KA, Pasinetti GM, Roberts JL, Mobbs CV. Transgenic neuronal expression of proopiomelanocortin attenuates hyperphagic response to fasting and reverses metabolic impairments in leptin-deficient obese mice. Diabetes. 2003 52(11):2675-2683.

95. Flowers MT, Ntambi JM. Stearoyl-CoA desaturase and its relation to high-carbohydrate diets and obesity. Biochim Biophys Acta. 2009;1791(2):85-91.

96. Cohen P, et al. Role for stearoyl-CoA desaturase1 in leptin-mediated weight loss. Science. 2002; 297(5579):240-243.

97. Dobrzyn A, Ntambi JM. The role of stearoyl-CoA desaturase in the control of metabolism. Prostaglandins Leukot Essent Fatty Acids. 2005;73(1):35-41.

98. Ntambi JM, et al. Loss of stearoyl-CoA desaturase-1 function protects mice against adiposity. Proc Natl Acad Sci U S A. 2002;99(17):11482-11486.

99. Zhang J, et al. Selective disruption of PPARgamma 2 impairs the development of adipose tissue and insulin sensitivity. Proc Natl Acad Sci U S A. 2004; 101(29):10703-10708.

100. Westerbacka J, et al. Genes involved in fatty acid partitioning and binding, lipolysis, monocyte/ macrophage recruitment, and inflammation are overexpressed in the human fatty liver of insulinresistant subjects. Diabetes. 2007;56(11):2759-2765.

101. Klaman LD, et al. Increased energy expenditure, decreased adiposity, and tissue-specific insulin sensitivity in protein-tyrosine phosphatase 1B-deficient mice. Mol Cell Biol. 2000;20(15):5479-5489.

102. Novak A, Guo C, Yang W, Nagy A, Lobe CG. $\mathrm{Z} / \mathrm{EG}$, a double reporter mouse line that expresses enhanced green fluorescent protein upon Cremediated excision. Genesis. 2000;28(3-4):147-155.

103.Liu $\mathrm{H}$, et al. Transgenic mice expressing green fluorescent protein under the control of the melanocortin-4 receptor promoter. J Neurosci. 2003; 23(18):7143-7154.

104.Paxinos G, Franklin KBJ. The Mouse Brain in Stereotaxic Coordinates. San Diego, CA: Elsevier Science Academic Press; 2004

105.Sutherland TM, Biondini PE, Ward GM. Selection for growth rate, feed efficiency and body composition in mice. Genetics. 1974;78(1):525-540.

106. Fisher SJ, Kahn CR. Insulin signaling is required for insulin's direct and indirect action on hepatic glucose production. J Clin Invest. 2003;111(4):463-468.

107. Singhal NS, Lazar MA, Ahima RS. Central resistin induces hepatic insulin resistance via neuropeptide Y. J Neurosci. 2007;27(47):12924-12932.

108. Guo L, Munzberg H, Stuart RC, Nillni EA, Bjorbaek C. N-acetylation of hypothalamic alpha-melanocytestimulating hormone and regulation by leptin. Proc Natl Acad Sci U S A. 2004;101(32):11797-11802.

109. Gamber KM, Macarthur H, Westfall TC. Cannabinoids augment the release of neuropeptide $\mathrm{Y}$ in the rat hypothalamus. Neuropharmacology. 2005; 49(5):646-652 